\title{
U.S. GEOLOGICAL SURVEY MAGNETOMETER \\ NETWORK AND MEASUREMENT TECHNIQUES IN \\ WESTERN U.S.A.
}

\author{
By \\ R.J. Mueller \\ M.J.S. Johnston \\ B.E. Smith \\ V. Keller
}

OPEN-FILE REPORT NO. $81-1346$

MENLO PARK, CALIFORNIA

1980

This report is preliminary and has not been

reviewed for conformity with

U.S. Geological Survey editorial standards.

Any use of trade names is for descriptive purposes only

and does not imply endorsement by the USGS 
Table of Contents

1.0 INTRODUCTION

1.1 Purpose

1.2 Proton Magnetometer

1.3 Geographical Station Selection

Page No.

3

3

3

4

2.0 DESCRIPTION OF MAGNETOMETER ARRAYS

2.1 Continuous Recording Array

2.2 Physical Site Description for Permanent Array

2.3 Five-Ten Day On-Site Recording Portable Array

2.4 Physical Site Description for Portable Array

2.5 Large Scale Survey Array

2.6 Physical Site Description for Survey Array

3.0 DESIGN DETAILS OF PERMANENT MAGNETOMETER STATION

3.1 General Details

3.2 Clock Oscillator

3.3 Magnetometer Modifications

3.4 General Description of Telemetry Transmission

3.5 Counter-Sequencer

3.6 Larse SEN Unit

3.7 F.S.K. Oscillator

6

3.8 Relay

3.9 Power

6

6

7

7

9

9

$\begin{array}{lll}4.0 & \text { DESIGN DETAILS OF PORTABLE MAGNETOMETER STATION } & 10\end{array}$

4.1 General Description 10

4.2 Recording System 11

4.3 Power

5.0 DESIGN DETAILS FOR MAGNETOMETER TELEMERY RECIEVER AND RECORDER SYSTEM

5.1 General Description

5.2 Discriminator

5.3 Switching Circuit

5.4 Larse REDE Unit

5.5 Data Acceptance

5.6 Time Decoder

5.7 Digital Recording System 14

5.8 Interface Sequencer 15

5.9 Analog Recording System 15

5.10 Differencer $\quad 15$

5.11 Trace Control 15

5.12 Analog Recorder 16

5.13 Power 16

$\begin{array}{ll}\text { REFERENCES } & 17\end{array}$

$\begin{array}{lr}\text { FIGURE CAPTIONS } & 18\end{array}$ 


\subsection{INTRODUCTION}

\subsection{Purpose}

Both laboratory measurements (Kalashnikov, 1954; Kapitsa, 1955; Oknaka and Kinoshita, 1968) and theoretical studies (Kern, 1961; Stacey, 1962; Nagata, 1970; Stacey and Johnston, 1972) indicate a change in stress causes a piezomagnetic effect in rocks containing magnetic grains. For simple models of earthquake processes changes of a few gammas can be expected in the magnetic field at the earth's surface due to earthquake-related stress changes (Shamsi and Stacey, 1969).

The U.S. Geological Survey is operating a network of proton magnetometers in an effort to detect and monitor tectonomagnetic related stress changes. Three different methods of measurement technique have been used within this network to obtain a compromise between geographical coverage and measurement resolution in areas of interest. The arrays that correspond to each technique are designated as permanent, portable, and survey arrays. The purpose of this report is to describe the three types of magnetometer arrays and show the location of the sites in each array.

\subsection{Proton Magnetometer :}

Free proton precession magnetometers are used in all of the magnetometer arrays. This particular type of instrument was chosen for its sensitivity (one quarter gamma) and long term stability. The basic operational principle of the proton magnetometer is derived from the dependence of precession frequency ( $f$ ) of the magnetic moments of free protons after excitation on the ambient magnetic field $(H)$ :

$$
2 \pi f=\gamma_{p H}
$$

Where $\gamma_{p}$ is the gyromagnetic ratio, an absolute constant (Driscoll and Bender, 1958; Vigoureux, 1962, 1963) adopted internationally as:

$$
Y_{p}=2.67513 \pm 0.00002 \times 10^{4} \mathrm{radians} / \mathrm{gauss} \mathrm{sec} \text {. }
$$

Therefore, the magnetic field can be measured directly in gammas by measuring the precession frequency:

$$
H=k f_{p}
$$

where the constant $K=23.4874(+0.0002)$. To measure the precession frequency, a coil surrounding a Tiquid hydrocarbon is polarized by sending a DC current through the coil. The magnetic moment vectors of the protons are partially aligned parallel to the applied field. When the applied field is removed suddenly the protons relax back to partial alignment with the local earth's magnetic field and will precess about this field direction. The precessing causes a small amplitude ( $\mu v)$ AC signal to be induced into the same coil used to polarize the protons. This precession frequency is filtered, amplified, multiplied, and counted to give an absolute value of the total field intensity of the earth's magnetic field. 


\subsection{Geographical Station Selection}

Several factors are considered when selecting areas for magnetometer

stations. The factors in order of importance are as follows:

1. Proximity to active faults.

2. Areas suspect of stress accumulation.

3. Areas of maximum tectonomagnetic effects as determined by

theoretical model studies.

4. Magnetic properties of surface geology.

5. Magnetic gradients suitable for detection of magnetic anomalies. Practical considerations include access to communications lines and physical access to the station.

\subsection{DESCRIPTION OF MAGNETOMETER ARRAYS}

\subsection{Continuous Recording Permanent Array}

The permanent magnetometer array consists of twenty-eight permanently positioned, battery powered, proton magnetometer systems which automatically and sychronously sample and telemeter measurements of the earth's magnetic field intensity. The stations are located 7 to $40 \mathrm{~km}$ apart, along the San Andreas fault system in central (Figure $1 A \& B$ ) and southern (Figure $2 A \& B$ ) California. The permanent magnetometer stations are placed in areas of anticipated tectonic activity and stress change, in search of tectonomagnetic effects with periods generally greater than one day. Each station consists of a proton magnetometer and telemetry system. The stations sample and telemeter a synchronized measurement of magnetic field intensity once every minute in Coordinated Universal Time (CUT). The telemetered data are transmitted via phone lines and radio links to Menlo Park, California where the data are received and 10 minute values are recorded onto a computer. Stations telemeter data once a minute to aid field maintenance and troubleshooting malfunctions. Each recorded 10 minute datum sample is differenced with the sample from an adjacent station to reduce effects caused by ionospheric and magnetospheric disturbances. A daily mean difference and standard deviation are calculated for each station pair. For station separations of less than 20 $\mathrm{km}$ a standard deviation of $0.75 \mathrm{gammas}$ is typical for differenced data during periods of quiet to unsettled geomagnetic field activity and typically less than 1.5 gammas during periods of active geomagnetic field. Six of the permanent stations have been operating since 1974.

\subsection{Physical Site Description for Permanent Array}

A permanent magnetometer station consists of redwood sensor post, fiberglass electronics enclosure, and aluminium battery enclosure (figure $3 \mathrm{~A})$. The $15 \times 15 \mathrm{~cm}$ sensor post is constructed by milling a $9.5 \mathrm{~cm}$ diameter hole $20 \mathrm{~cm}$ deep in one end and cutting a $2 \times 2.5 \mathrm{~cm}$ slot along the entire length of the post. The top is covered with a square piece of $0.3 \mathrm{~cm}$ thick plastic attached to the post with nylon bolts. The magnetometer sensor is placed in the milled hole and the sensor cable is enclosed in $1.3 \mathrm{~cm}$ plastic conduit and placed in the $2.5 \mathrm{~cm}$ slot. A $0.3 \mathrm{~cm}$ thick wood strip is glued over the conduit sealing it inside the post. The sensor cable is enclosed in the conduit between the sensor post and the electronic enclosure. 


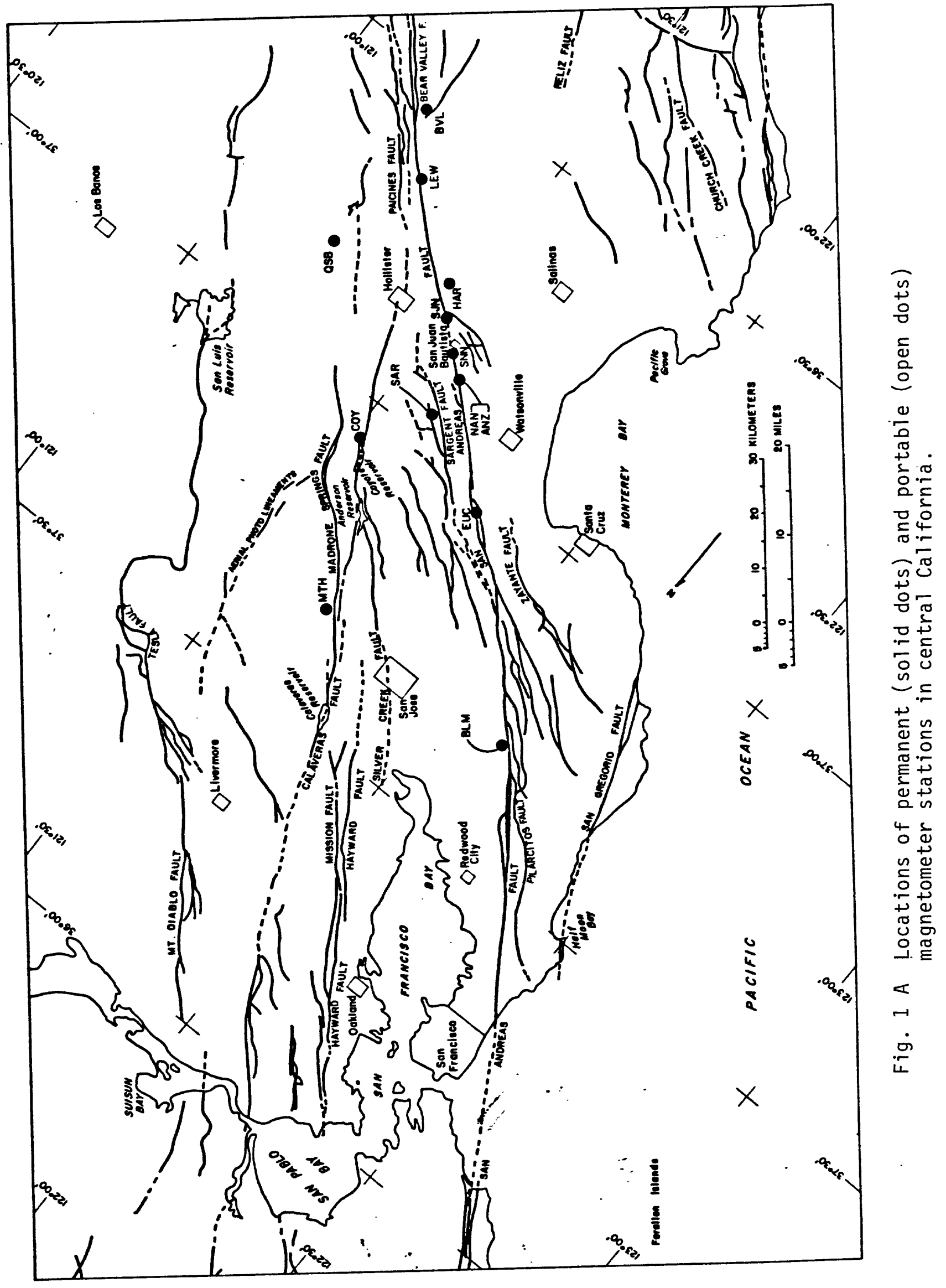




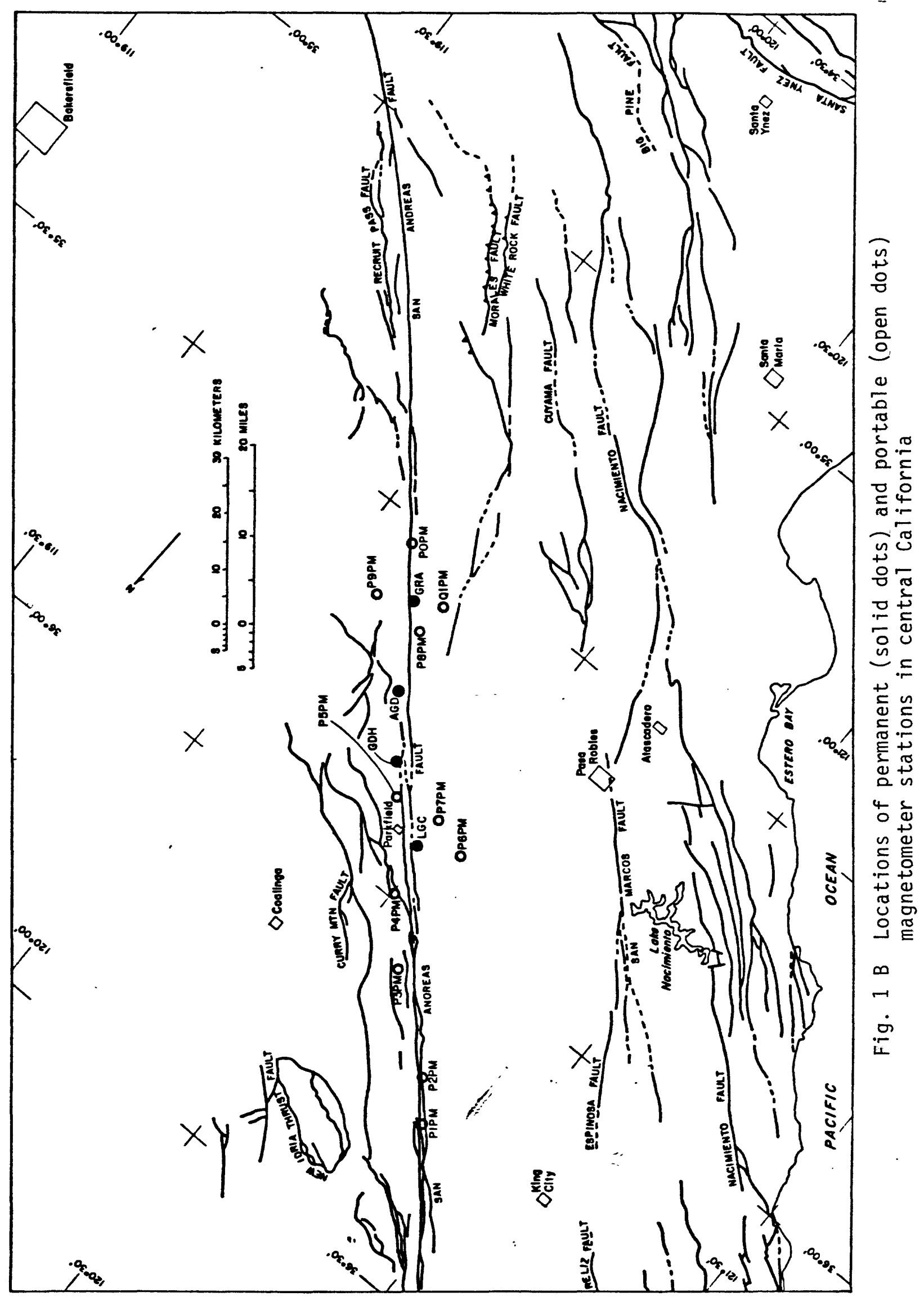




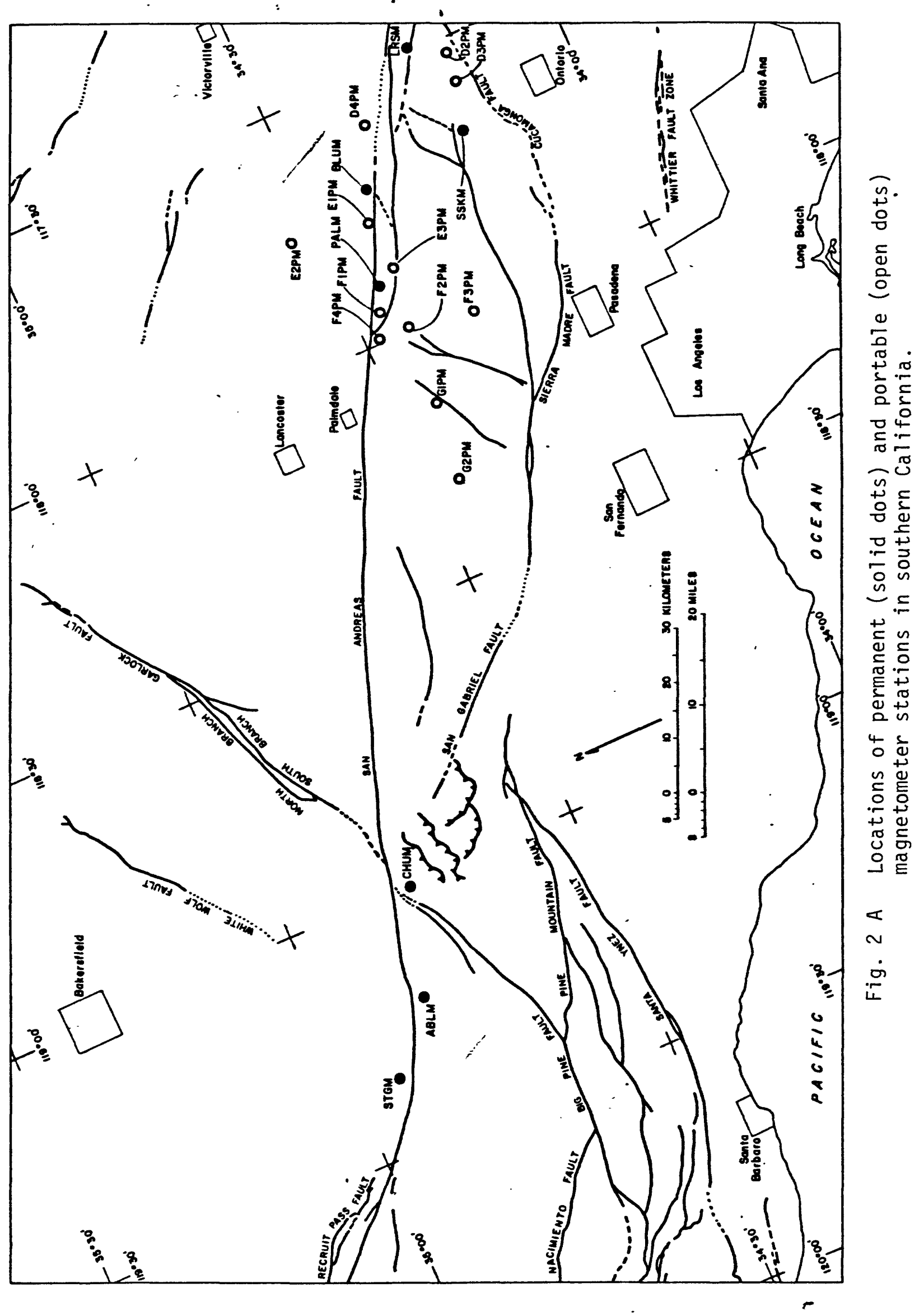




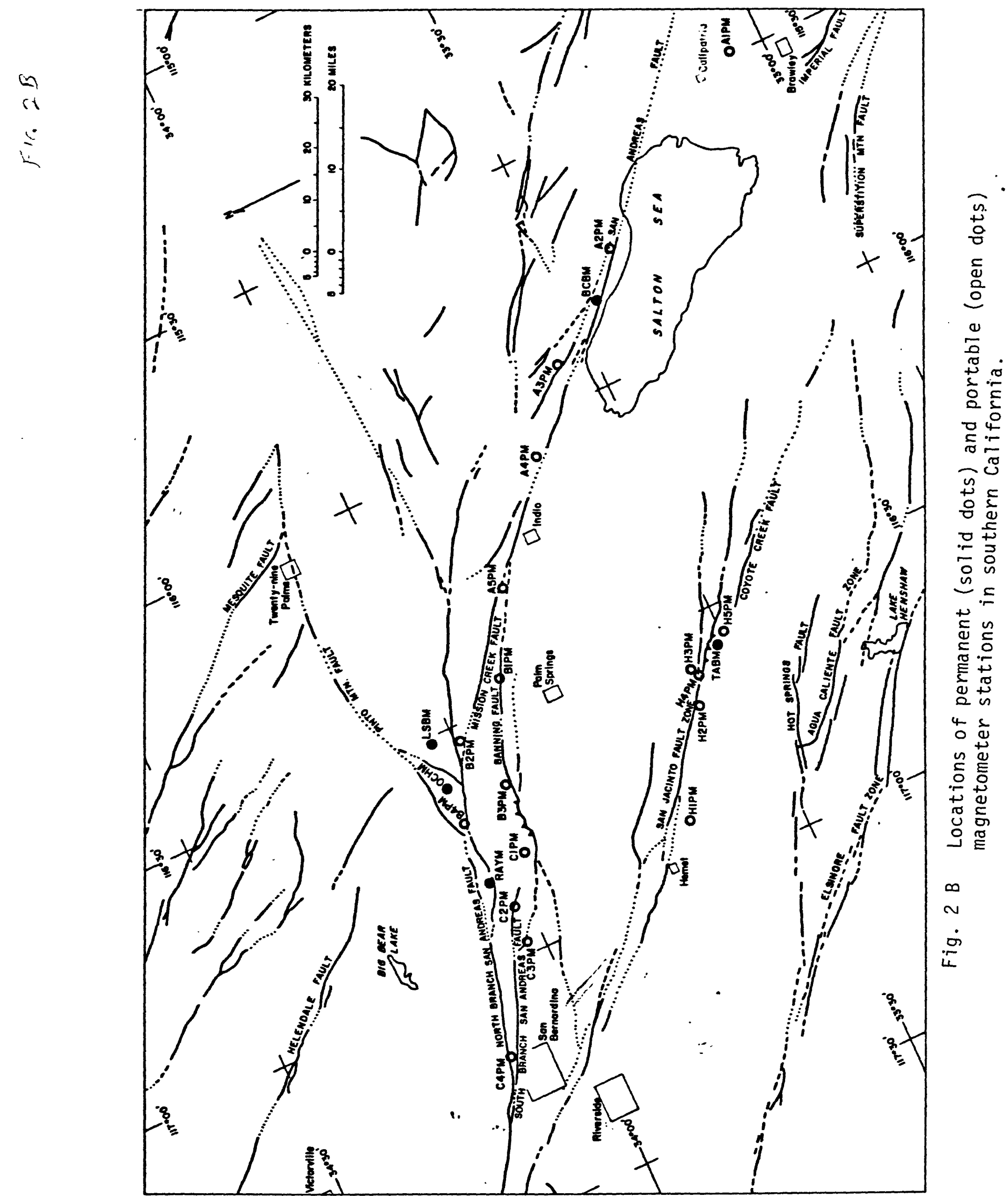




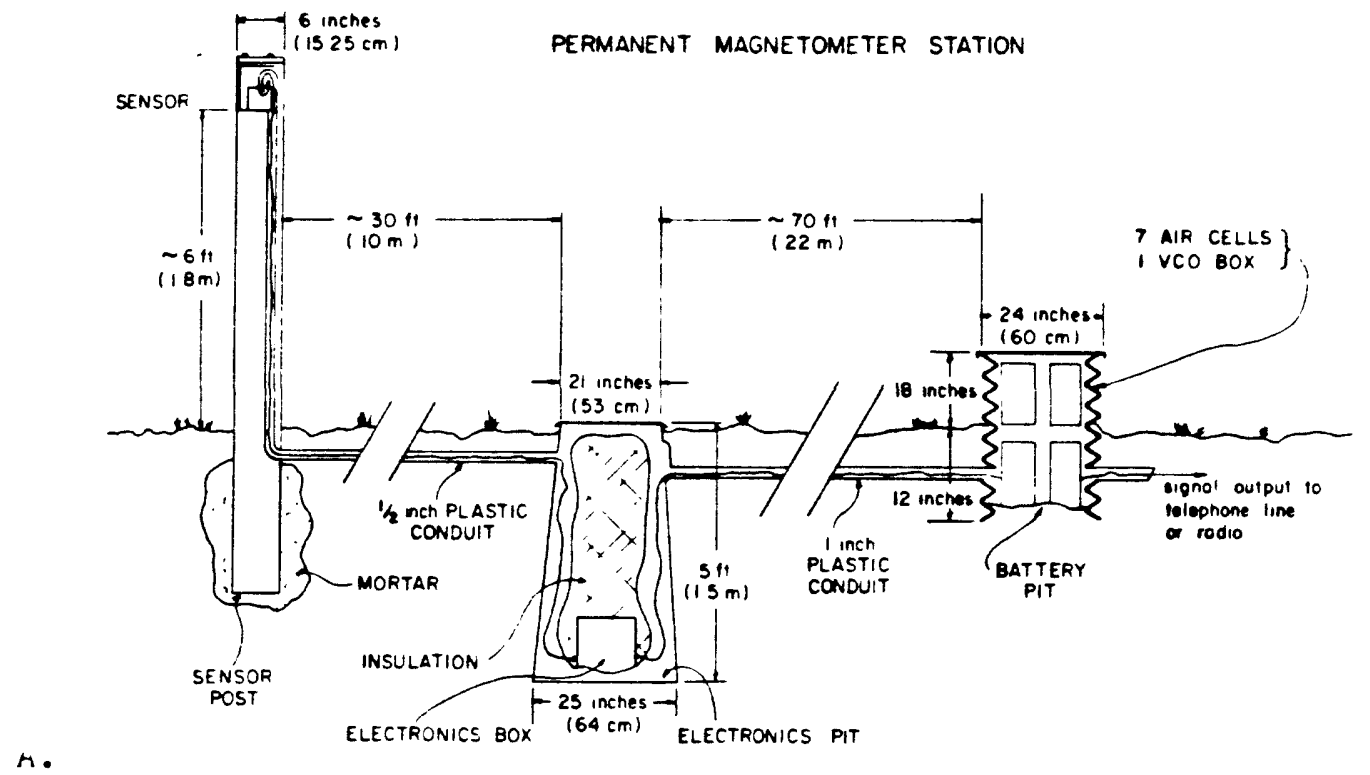

B.

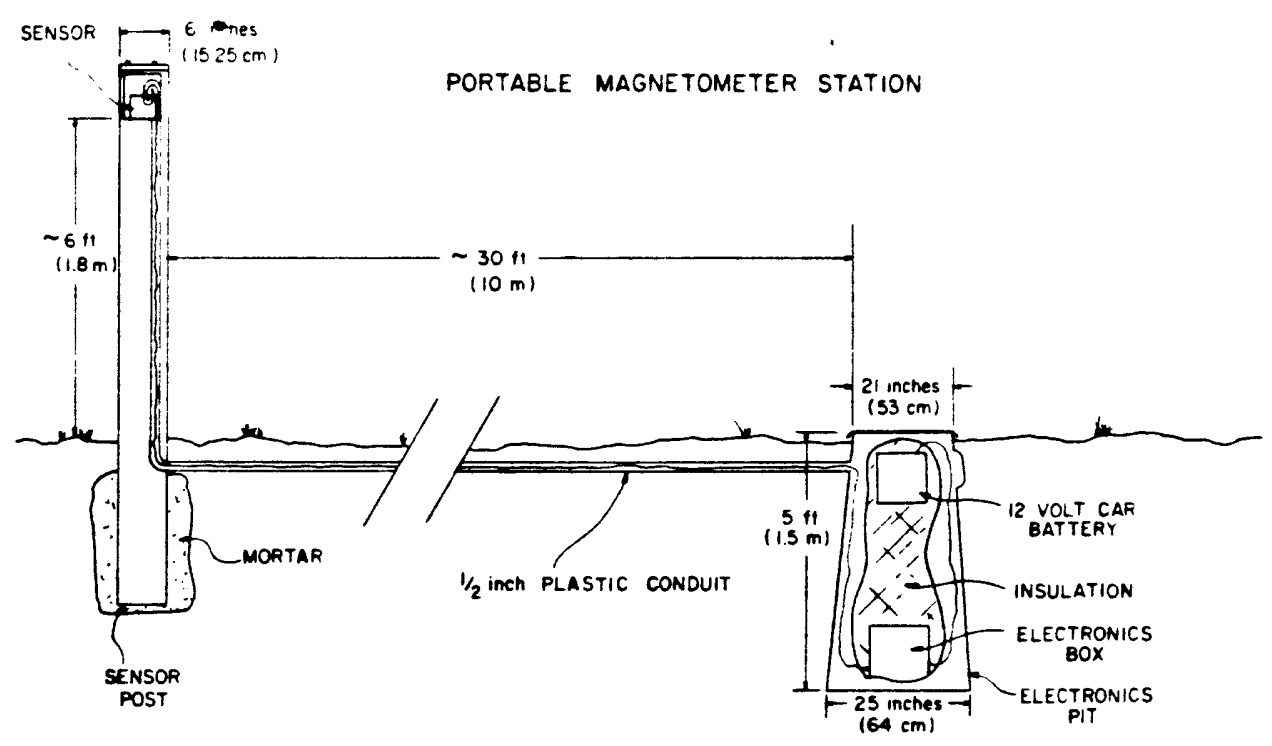

SURVEY MAGNETOMETER STATION

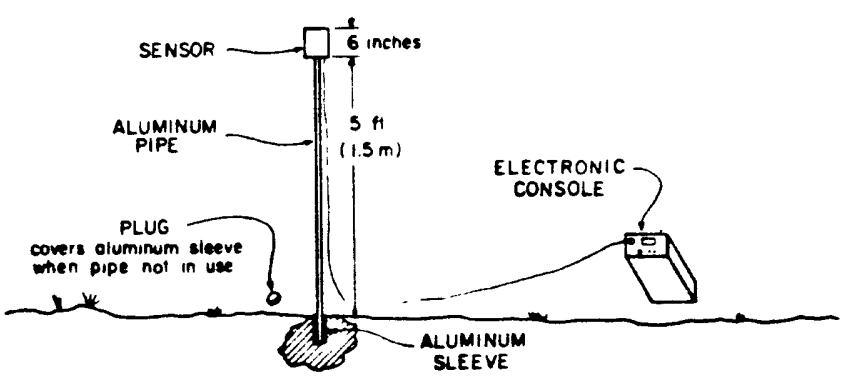

Fig. 3 Illustration of permanent (A), portable (B), and survey (C) 
The fiberglass electronics enclosure is watertight, $1.5 \mathrm{~m}$ deep, and tapered to prevent hydraulic pressure caused by ground water from forcing the enclosure out of the ground. A form fitted lid covers the enclosure and is held with stainless steel bolts. The depth of the enclosure and a nylon bag filled with stryofoam pellets serve to stabilize the temperature environment of for the electronics. A rectangular box (check box) at the top of the electronics enclosure contains all inputs and outputs, with the exception of the sensor cable.

With the exceptions of the sensor, FSK oscillator, and relay, all the electronics are placed on the bottom of the electronics enclosure inside a waterproof, fiberglass case (figure 4). The power in and data out are connected through a $2.5 \mathrm{~cm}$ plastic conduit buried between the electronics enclosure and the battery enclosure.

The battery enclosure is an open bottom aluminum culvert with an aluminum lid. The enclosure contains seven air cell batteries and a fiberglass case containing the FSK oscillator and relay (Figure 5).

Where possible, the stations are made as inconspicious as possible by placing the sensor post in or near wooded areas and camouflaging the enclosures with spray paint (Figure 6).

\subsection{Five-Ten Day on Site Recording Portable Arrays}

The portable magnetometer array consists of a proton magnetometer and on site recording system. The portable array is designed for special studies and to search for longer period ( $>6$ months) tectonomagnetic effects. The portable magnetometer system enables rapid installation for short term studies without the time and expense of installing telemetry. The portable station sites may easily be converted to permanent magnetometer stations. The stations are located 5 to $15 \mathrm{~km}$ apart in seismically active areas of tectonomagnetic interest (figures 1 and 2). Presently 55 of the proposed 75 stations have been installed and data have been collected since 1978. A set of five portable on site recording magnetometer systems are sychronously operated for a period of 5 to 10 days at a 10 minute sample interval. At the end of the recording period, four of the five stations are moved to new locations leaving one station common to the two recording periods. The portable magnetometer stations sample sychronously in phase with Coordinated Universal Time (CUT) recording the data and time on a digital impact printer. With a 10 minute sample interval a portable magnetometer station can operate for 50 days powered with a 12 volt car battery. The data from the digital printer are key punched and read into a computer. A mean difference and standard deviation are computed for each station pair. Standard deviation of 0.5 gamma over the 5 to 10 day recording period is typical for differenced data during periods of quiet to unsettled geomagnetic field and less than 1.0 gamma during periods of active geomagnetic field. 


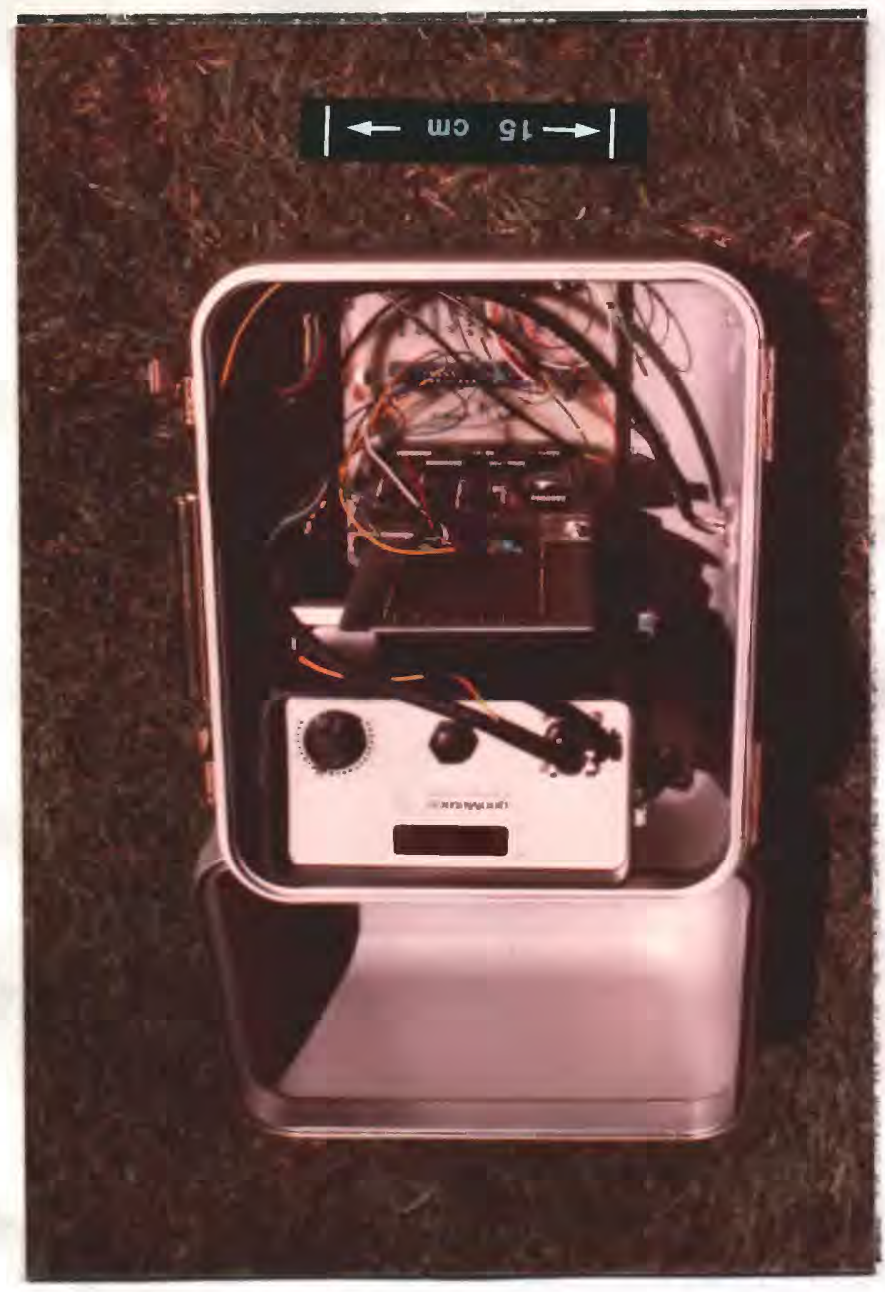

Fig. 4 Electronics case for a permanent magnetometer station

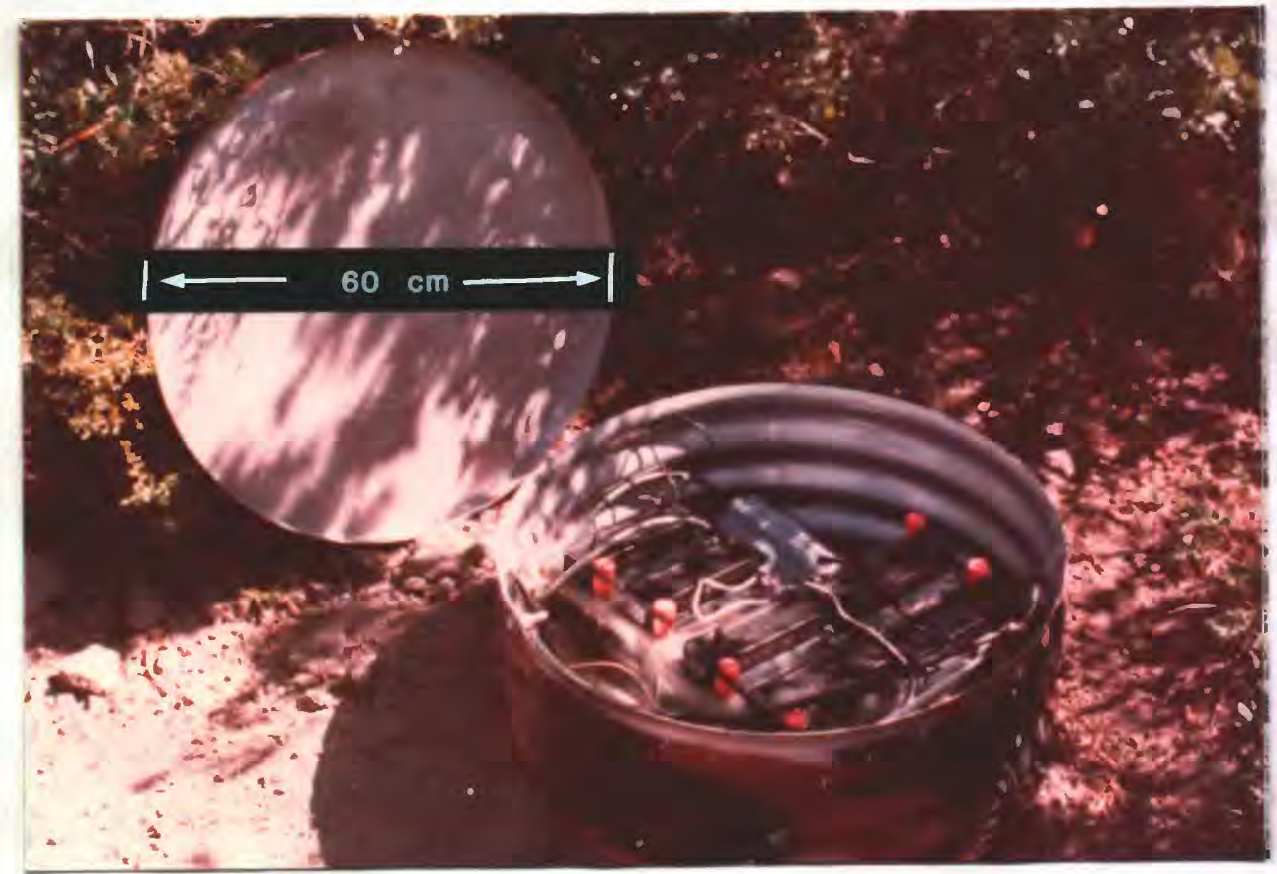

Fig. 5 Battery enclosure for permanent magnetameter station. 


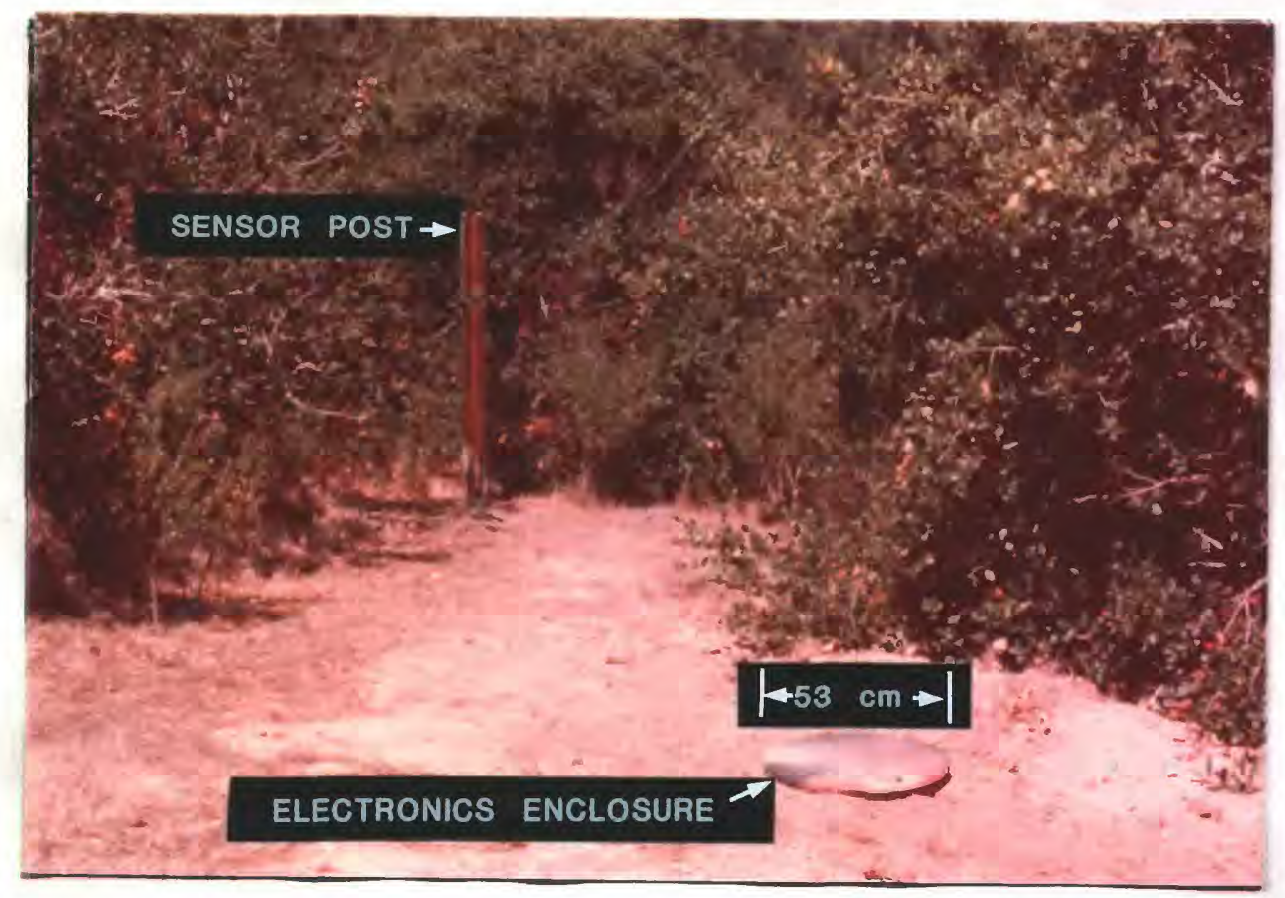

Fig. 6 Sensor post and electronics closure at a permanent magnetometer station.

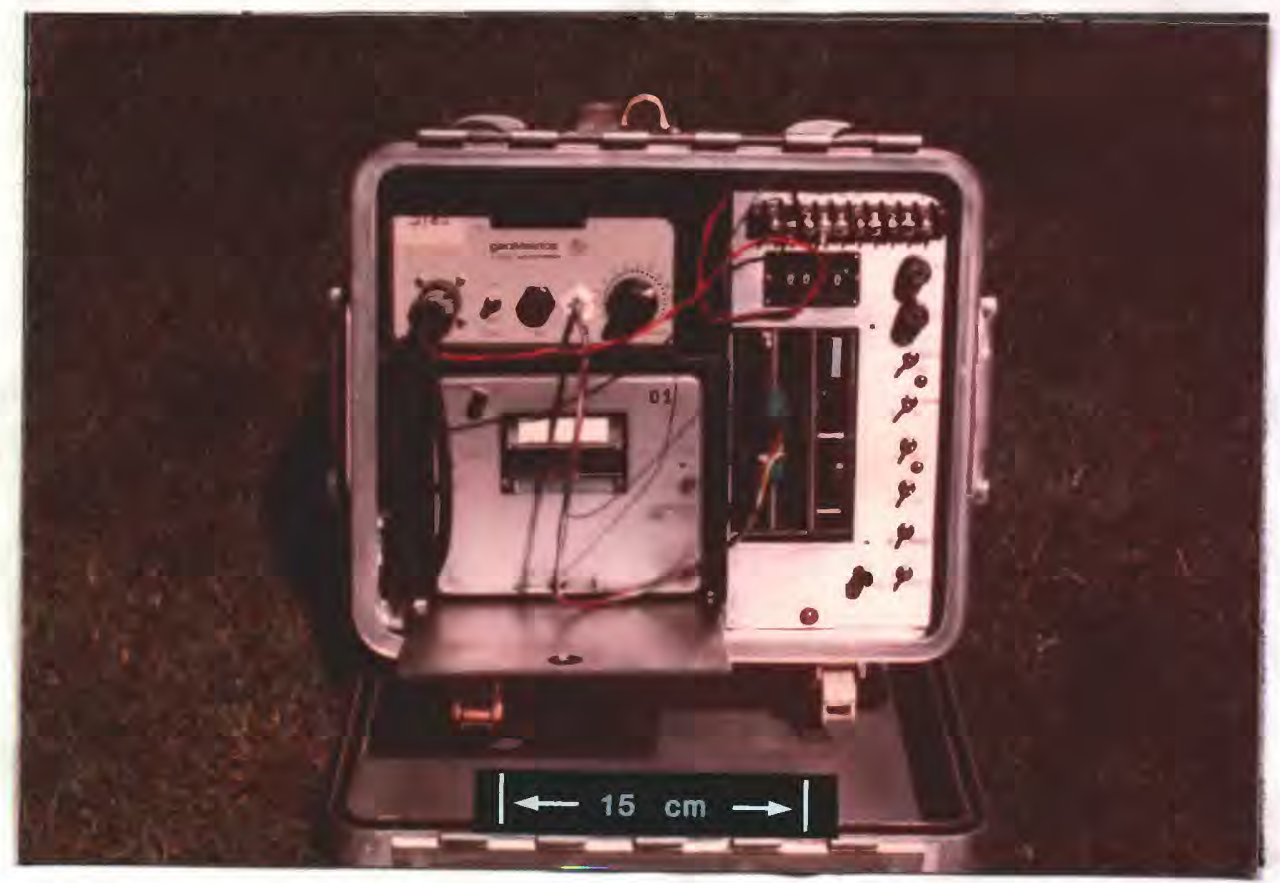

Fig. 7 Electronics case for a portable magnetometer station. 


\subsection{Physical Site Description for Portable Array}

A portable magnetometer station consists of a wooden sensor post and fiberglass electronics enclosure identical to a permanent magnetometer station. A portable station does not have a battery enclosure (Figure $3 b$ ). All electronics except the sensor and batteries are contained in an aluminum case (Figure 7), placed on the bottom of the electronics enclosure, and covered with the nylon bag filled with styrofoam insulation. The two batteries powering the station, are placed on top of the insulation bag.

\subsection{Large Scale Survey Arrays}

The survey magnetometer array consists of 97 stations located 10 to $20 \mathrm{~km}$ apart along the San Andreas fault, Garlock fault, San Jacinto fault, Owens Valley and parts of Nevada (Figure 8 ). The survey array is designed to search for broad-scale long-period ( $>12$ months) tectonomagnetic effects (Johnston, 1974). Data are collected every 6 or 12 months, by manually operating a pair of proton magnetometers. The magnetometers synchronously sample the earth's magnetic field intensity over a 10 minute period and are moved in a "leap frog" fashion along the array. The averaged data for each 10 minute period from each adjacent pair of stations is differenced and standard deviation is calculated. The survey arrays have been surveyed since 1974. The largest standard deviation for individual sets of data is 1.5 gammas and typically less than 0.75 gamma (Johnston et al, 1976). With the survey method a large geographical area can be covered rapidly with relatively low equipment and personnel cost. However, the resolution is not as great as for the portable array because of the shorter time base.

\subsection{Physical Site Description for Survey Array}

The survey magnetometer station consists of an aluminum pipe permanently driven in the ground. An aluminum staff which holds the magnetometer sensor is placed in the pipe while the magnetometer is manually cycled during the survey (Figure $3 c$ ).

\subsection{DESIGN DETAILS FOR PERMANENT MAGNETOMETER STATIONS}

\subsection{General Details}

Figure 9 is a block diagram of a permanent magnetometer station. Low power CMOS circuitry is used throughout the system, with the exception of the Larse sen unit. Commerical components purchased for the system are the proton magnetometer (model G-816 or G-826) and sensor by Geometrics, Inc. of Santa Clara, California, and the Larse sen unit (sen 171-60-1 a) produced by the Larse Corporation of Santa Clara, California. All other circuits are developments of the U.S. Geological Survey by G. Jensen, R. Mueller, and B. Smith. The permanent magnetometer station is functionaliy divided into two sections: (1) the magnetic field measurement and (2) the telemetry. The step by step procedure to sample and telemeter a measurement of the magnetic field intensity is as follows (figure 9): 


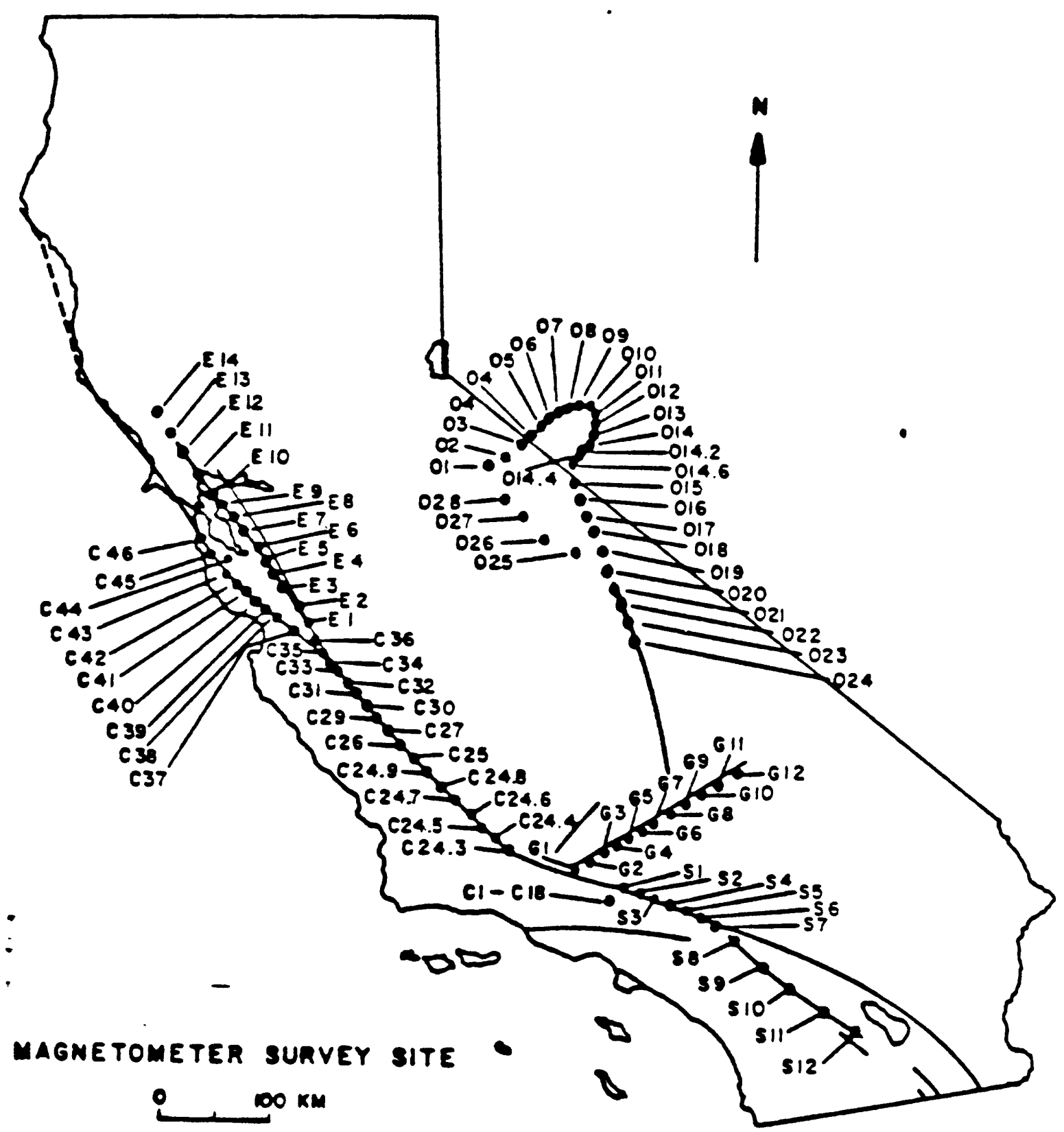

Fig. 8 Location of survey magnetometer stations in California and western Nevada. 
U.S.G.S. PERMANENT MAGNETOMETER STATION

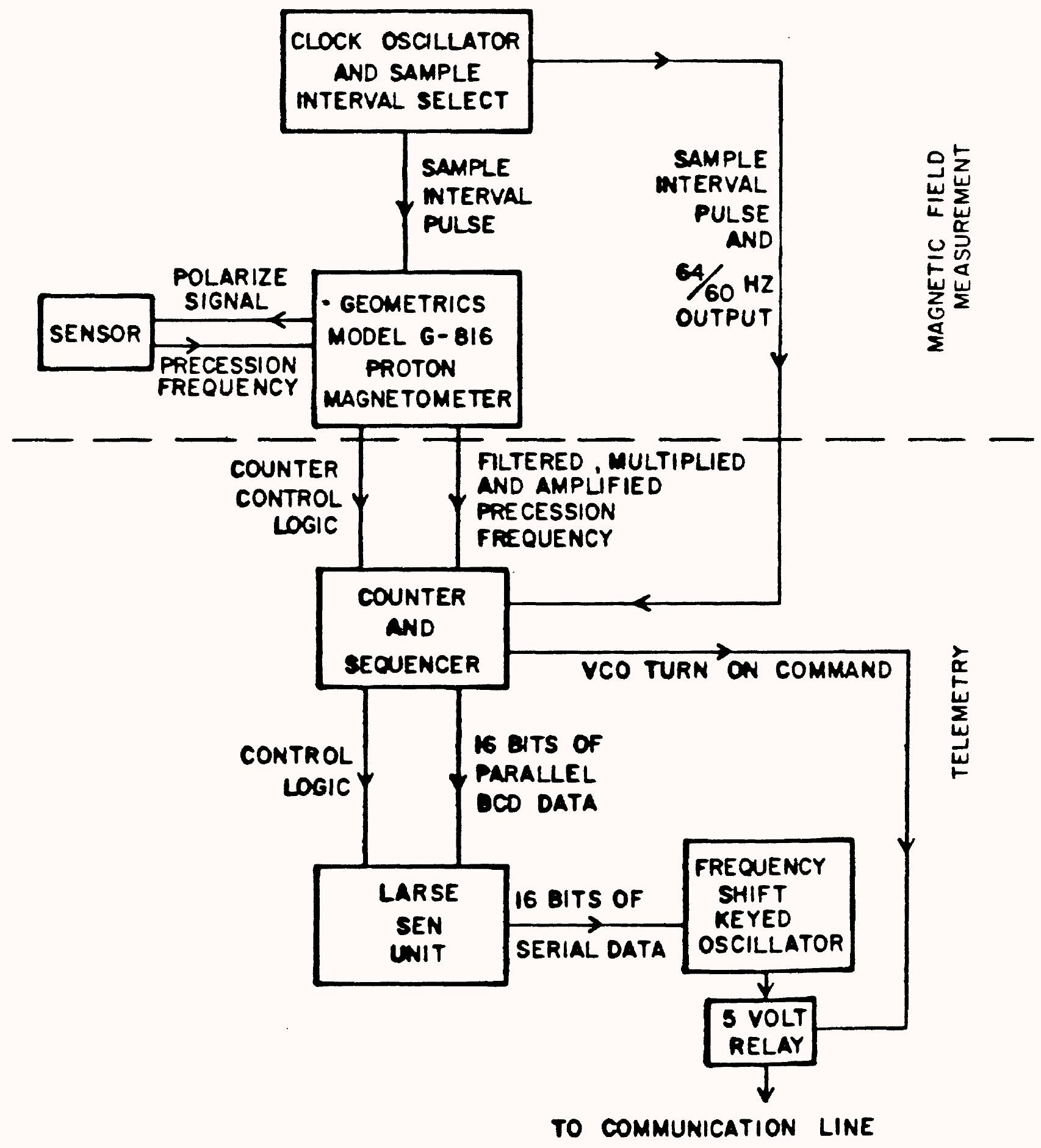

Fig. 9 Block diagram of permanent magnetometers. 
1. The clock oscillator automatically cycles the magnetometer and starts the counter-sequencer logic.

2. The magnetometer polarizes the sensor and at a precise time after polarization filters, amplifies, and multiplies the frequency of the proton signal.

3. The counter-sequencer circuit counts the frequency of the proton signal and holds 16 bits of parallel BCD output.

4. The 5-volt relay switches the output of the frequency shift keyed (FSK) oscillator onto the communication link.

5. The Larse sen unit receives and converts the parallel data to serial and transmits the data to the input of the FSK oscillator.

6. The FSK oscillator modulates the serial data between two audio carrier frequencies for transmission through a communication link.

7. A command from the counter-sequencer circuit turns the telemetry off and resets the logic.

\subsection{Clock Oscillator}

Differential magnetometer data requires timing accuracy for data sampling. A low power $(\sim 140 \mathrm{mw})$ temperature compensated crystal oscillator (clock oscillator) provides the accuracy. The outputs from the clock oscillator control the timing of data sampling and telemetry transmission. The clock oscillator provides adjus table CMOS compatible outputs of $1 / 60 \mathrm{~Hz}$ and $64 / 60 \mathrm{~Hz}$, less than $+0.1 \mathrm{ppm}$ variation between $+4^{\circ} \mathrm{C}$ and $+25^{\circ} \mathrm{C}$, and an aging rate less than 5 parts in 107 per year. Sample times are maintained at $+200 \mathrm{msec}$ by adjustment and reset every 30 to 60 days. The oscillator is adjusted and reset in phase with CUT by comparison with a more accurate, portable, oven controlled crystal oscillator (Hewlett-Packard 1055A). The clock oscillator is mounted on a printed circuit (PC) board with a CMOS divider circuit (IC 4-7) providing a selection of sample intervals ranging from one minute to four hours (figure 10). The output of the divider triggers a one shot (IC 2, C04047AE) providing a positive 12 VDC square pulse of 0.5 second duration (sample interval pulse). The leading edge of the sample interval pulse is in phase with 00 seconds CUT. The sample interval pulse is used to cycle both the magnetometer and telemetry transmission logic.

\subsection{Magnetometer Modifications}

The Geometrics model G-816 or G-826 proton magnetometer is the one component common to the three types of magnetometer arrays. The Geometrics magnetometer is a small, rugged, low power ( $8 \mathrm{~W}$ maximum) unit consisting of a sensor and an electronic console (figure 11). The magnetometer is designed for portable, battery powered, field use and can be operated by pressing a button on the console to display a measurement of the magnetic field intensity. The magnetometer is a proton precession type (see proton magnetometer section) and measures total field intensity in gamma units (1 gamma $=10-5$ gauss). Four modifications are made to the standard version of Geometrics magnetometer before being placed in a permanent magnetometer station: 


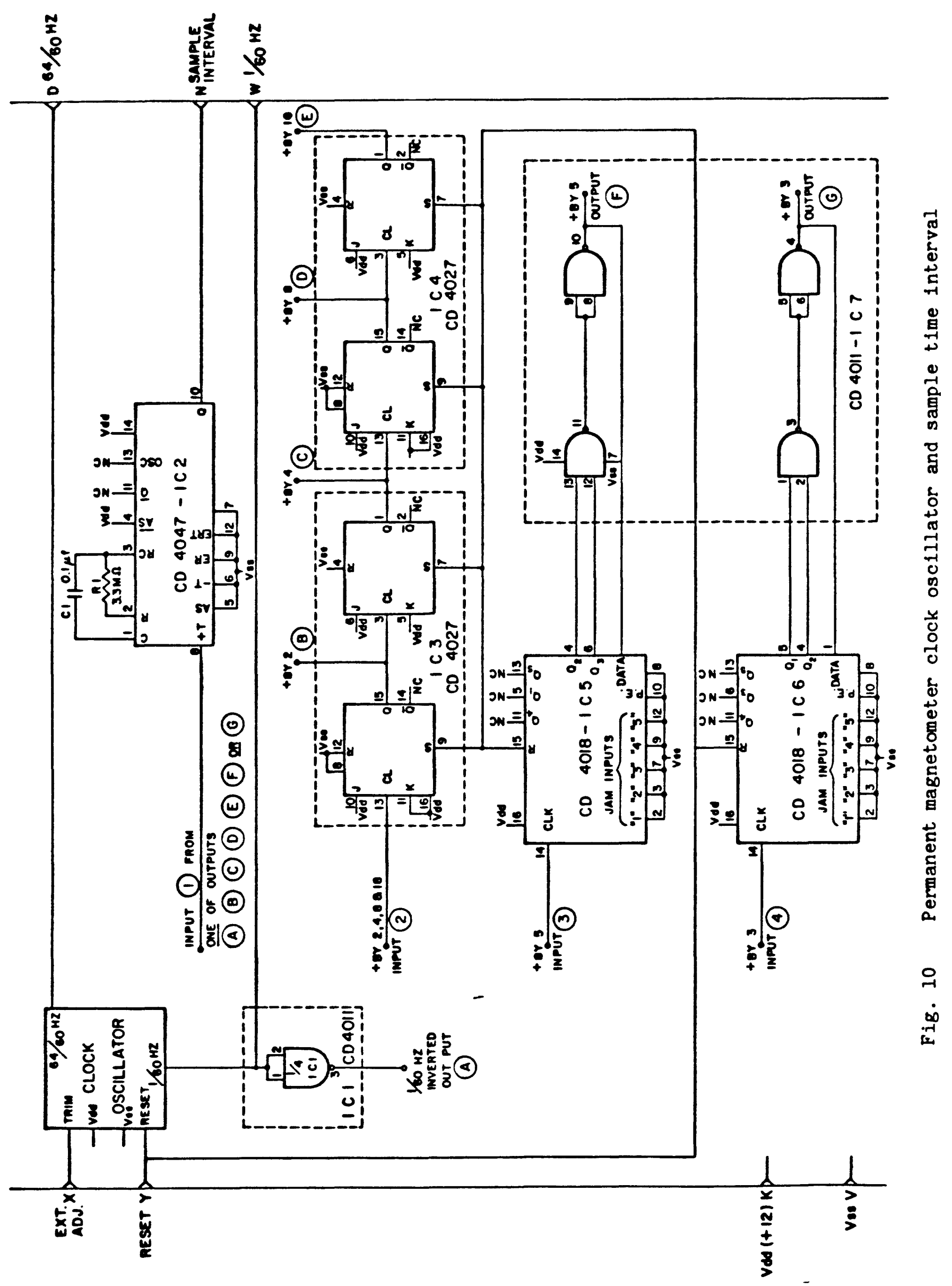




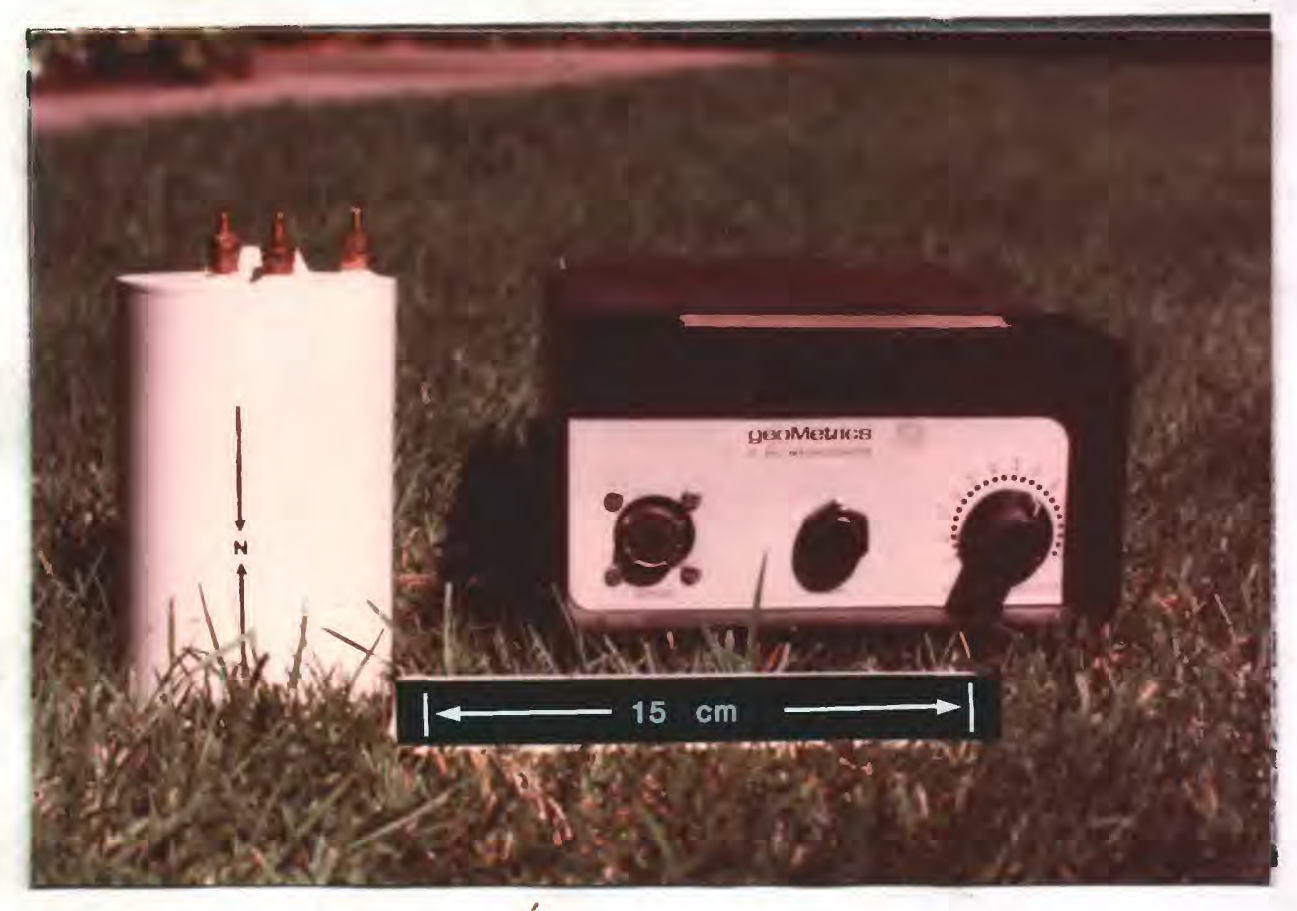

Fig. 11 Geometrics model G-816 electronic console and sensor.

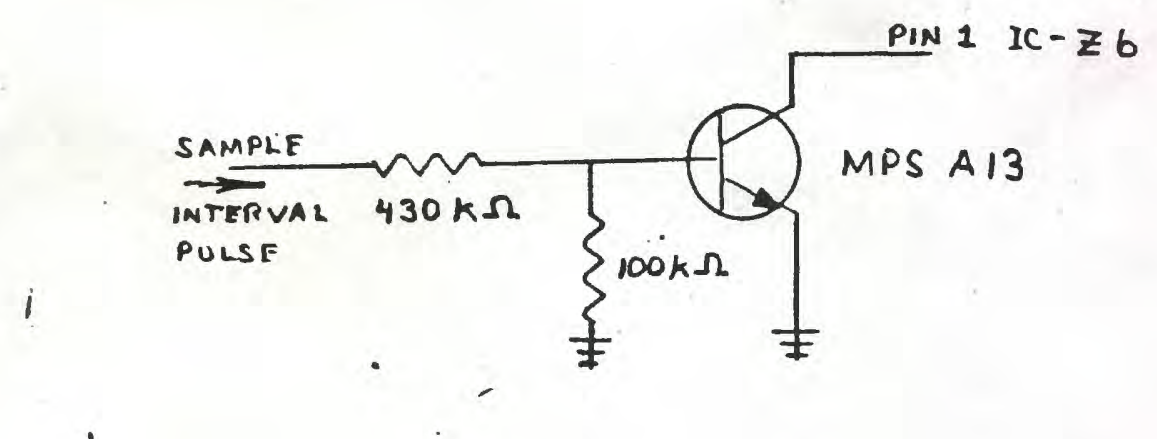

Fig. 12 Circuit allowing automatic cycling of the model G-816. 
1. An automatic cycling input is added.

2. The sensitivity is converted from +1.0 gamma to +0.25 gamma.

3. The original reference oscillator is replaced with a more accurate adjustable crystal osciallator.

4. The measured frequency of the proton signal is converted to binary coded decimal ( $B C D$ ) for telemetry compatibility.

Automatic cycling is controlled by a crystal oscillator (see clock oscillator section). The sample interval pulse from the clock oscillator cycles the magnetometer by switching a transistor between pin 1 of IC Z6 and ground (figure 12 and 13). The internal timing of the magnetometer completes the process of taking a measurement of the magnetic field intensity.

A change in sensitivity from \pm 1.0 gamma to \pm 0.25 quarter gamma is made by increasing by a factor of four the time period in which the multiplied frequency of the proton signal is counted. The change is made by moving the output of IC Z4 from pin 15 to pin 2 (figure 13).

The original reference oscillator, allowing the magnetometer an accuracy of \pm 1.0 gamma from $0^{\circ} \mathrm{C}$ to $50^{\circ} \mathrm{C}$, is replaced with an adjustable, temperature compensated crystal oscillator allowing an accuracy of +0.1 gamma over the same temperature range. The oscillator does not increase the sensitivity of the magnetometer which is dependent on the period of frequency measurement and the signal to noise ratio of the proton signal from the sensor, but increases the stability of the reference oscillator by decreasing the error due to drift caused by temperature changes and ageing. The new oscillator is adjusted every six to twelve months using the portable, oven controlled crystal oscillator (see clock oscillator section) as a reference.

The multiplied frequency of the proton signal is counted in the magnetometer by five decade counters (IC Z20-Z24 CD4033AE) having seven segment outputs that drive a display (figure 13). Seven segment output is incompatible with the BCD inputs of the Larse sen unit. To convert the data an external frequency counter controlled by the inputs to the decade counters is used. The external counter is on the counter-sequencer circuit (figure 14) and uses two dual-BCD counters (IC 2 and 3, CD45I8AE) to provide 16 bits of data representing the four least significant digits of the magnetic field intensity in one quarter gamma units. The 16 bits of output from the counter are converted to TTL compatible logic with three buffer chips (IC 4-6, CD4050AE). The data are now compatible with the Larse sen unit and are held at the outputs of the counter-sequencer circuit until a new measurement of the magnetic field intensity is taken.

This completes the part of the electronic system that automatically samples the magnetic field intensity. The remainder of the system is designed to telemeter the data through communication lines to Menlo Park, California. The conversion of data from seven segment to BCD is actually part of the telemetry system, but is explained above because the control logic and precession frequency are obtained from the magnetometer. 


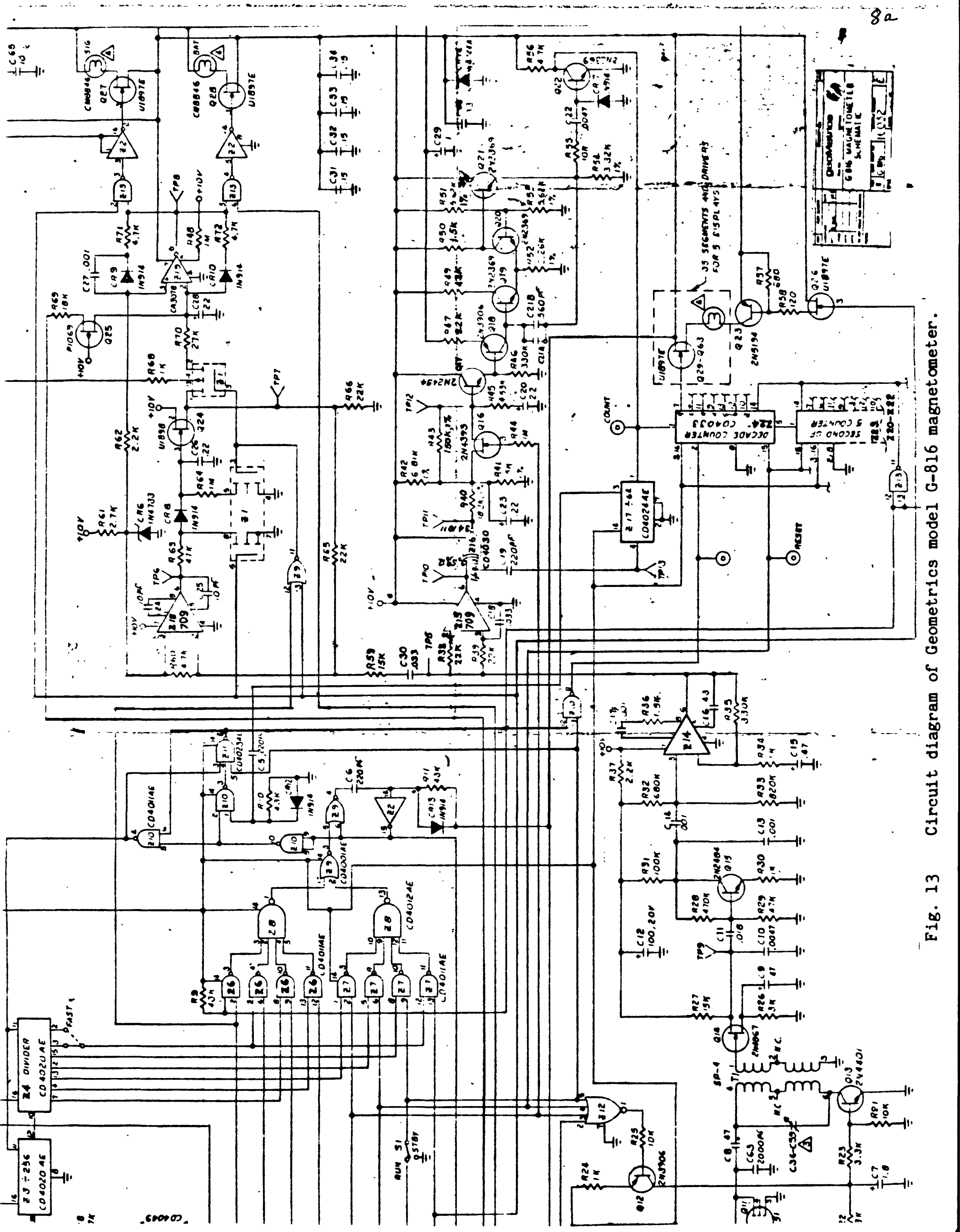


3.4 General Description of Telemetry Transmission

Transmitting the data from field stations to Menlo Park, California is accomplished using digital telemetry frequency shift keyed (FSK) onto telephone lines, radio links or a combination of both. Stations are multiplexed on the same communications line using different FSK frequency ranges and are time shared by sequentially transmitting at one frequency range. Four basic units are required for the telemetry system (figure 4):

1. The counter-sequencer circuit.

2. The Larse sen unit.

3. The frequency shift keyed (FSK) oscillator.

4. The relay.

\subsection{Counter Sequencer}

The counter-sequencer circuit is a low power (<70 mw) CMOS circuit designed to count the precession frequency of the proton signal and control the transmission timing of the telemetry (figure 9). Sequential timing is controlled by counting and decoding the $64 / 60 \mathrm{~Hz}$ output from the clock oscillator. This allows the data to be transmitted a preselected number of $64 / 60 \mathrm{~Hz}$ cycles $(0.9375 \mathrm{sec} / \mathrm{cycle})$ after the sample interval pulse. The number of $64 / 60 \mathrm{~Hz}$ pulses is determined by hard wiring the transmission ID on the counter-sequencer circuit (figure 14). Sequential transmission allows stations to sample at identical times, but to transmit data at different times. The sample interval pulse (see sections on clock oscillator) switches the output of a J-K flip flop (IC 7, CD4027AE) which enables two decade counters (IC 8 and 9, CD4017AE) to count the $64 / 60 \mathrm{~Hz}$ signal. The outputs of the two counters are decoded providing logic pulses for controlling telemetry transmission timing (figure 14 and 15):

1. The first pulse activates the relay switching the FSK frequency on to the communication link (relay command).

2. The second pulse powers up the Larse sen unit (warm up command).

3. The third pulse is a negative transition commanding the Larse sen unit to convert the data (send command).

4. The fourth pulse turns off and resets the telemetry transmission logic (turn-off reset command).

The relay command applies +12 VDC to a +5 VDC regulator (LM109H) switching the relay (Magnecraft W171-25) which gates the FSK frequency onto the communication link. The command also switches power to a radio transmitter, if used. The relay command can be selected from 3.7 seconds to 50.6 seconds after the sample interval pulse, allowing eight stations at a one minute sample interval to be sequenced on one communication link without changing the FSK frequency range (Figure 16).

The warm up command switches +12 VDC to power the Larse sen unit prior to giving the send command. The warm-up command is given 0.9375 seconds (one $64 / 60 \mathrm{~Hz}$ cycle) after the relay command.

The send command is a negative transition from +5 to 0 VDC and occurs 0.9375 seconds after the warm-up command. The command causes the Larse sen unit to convert the parallel data to serial for transmission through a single communication line.

The turn-off reset command terminates the above three command pulses and resets the electronics on the counter-sequencer circuit (figure 15). 


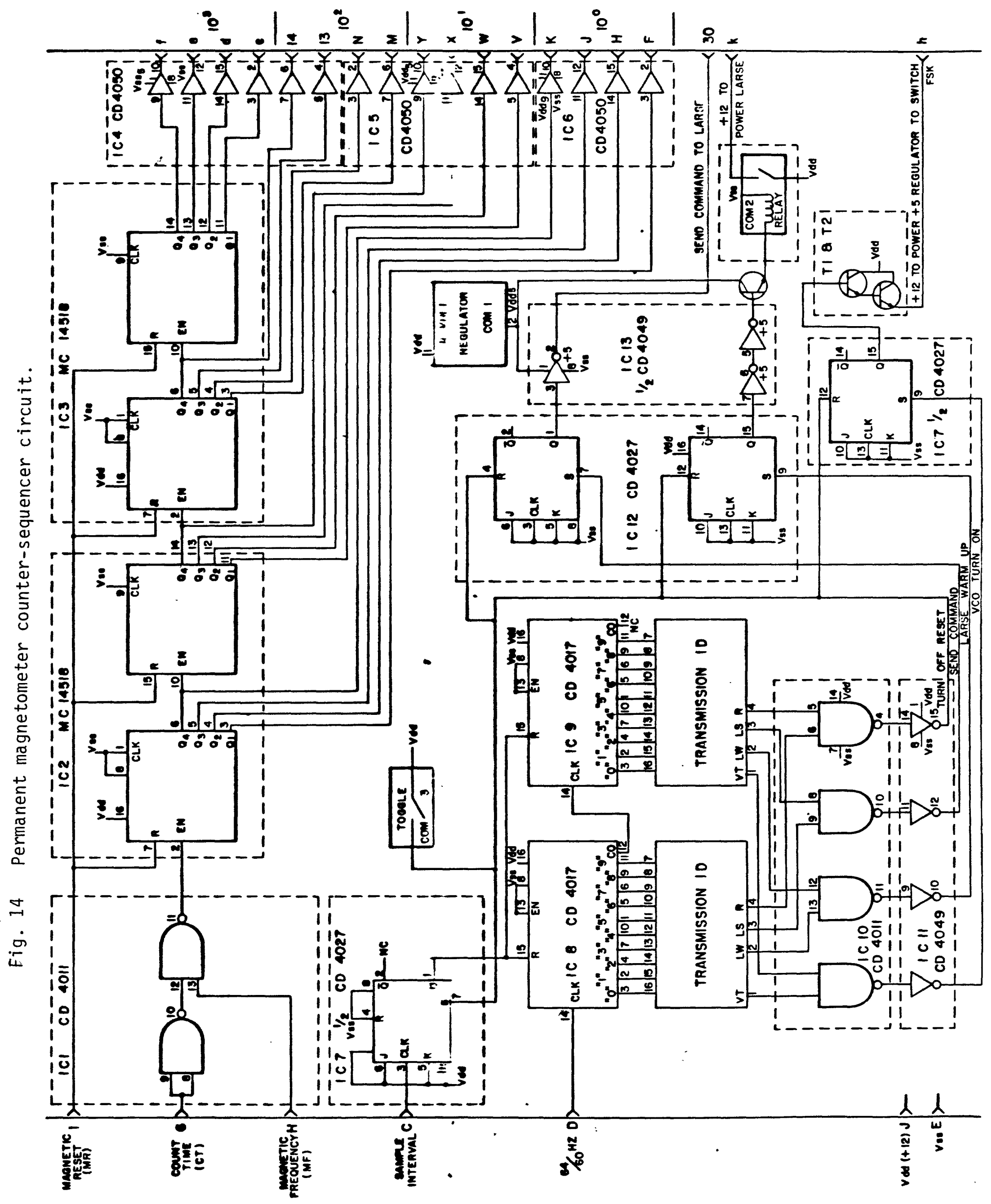


SAMPLE INTEKJAL

$$
6460 \mathrm{HZ}
$$

ENABLE ROR YOI75
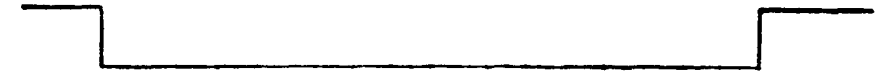

VCO TUAN ON

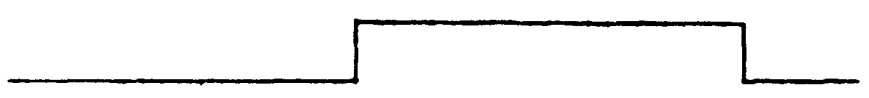

LARSE WARM UP

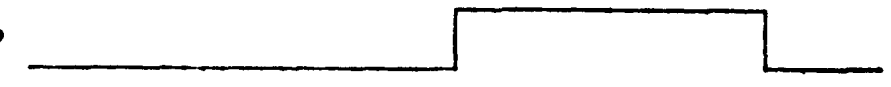

LARSE SEND

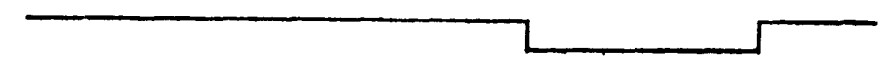

TRANMISSION I.D.

WIRED FOR:

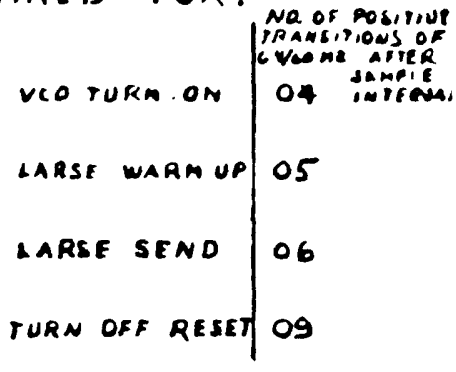

TURN OFF RESET

Fig. 15 Timing diagram for counter-sequencer circuit.

\begin{tabular}{|c|c|c|c|c|c|c|c|c|c|c|c|c|c|c|c|c|c|c|c|c|c|c|c|c|c|c|c|}
\hline Btotion: & & 1 & & $c$ & ? & & & 3 & & & & $f$ & & & 5 & & & & 0 & & & 7 & & & 8 & & \\
\hline Comends & \begin{tabular}{l|l|l|}
$V I$ & $L W$ \\
\end{tabular} & LSS $R$ & 1 & & 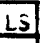 & & & & b $R$ & & $=\pi$ & 100 & R & & & $k$ & vi & & L L & & & LIII & \begin{tabular}{|l|l} 
& $R$ \\
\end{tabular} & & ILw & & R \\
\hline $\begin{array}{l}\text { Tiee efter semplo } \\
\text { intervel in } \\
\text { ooconde. }\end{array}$ & 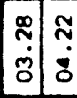 & $\begin{array}{lll} & 5 \\
8 & 5 \\
\end{array}$ & 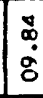 & $\begin{array}{l}\infty \\
? \\
\vdots \\
0\end{array}$ & & $\stackrel{n}{0}$ & $\begin{array}{l}3 \\
\\
\end{array}$ & 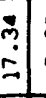 & $\begin{array}{l}0 \\
0 \\
0\end{array}$ & & $\vec{n}$ & dि & : & $\begin{array}{l}0 \\
\\
\vdots \\
\end{array}$ & $\begin{array}{ll}0 \\
\vdots \\
0\end{array}$ & 3 & $\mid \begin{array}{l}0 \\
0 \\
0 \\
0\end{array}$ & & $\begin{array}{l}\dot{a} \\
\dot{m} \\
\end{array}$ & : & & ?. & 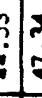 & & $\begin{array}{c}0 \\
\vdots \\
\end{array}$ & $\begin{array}{c}0 \\
\vdots \\
\dot{n}\end{array}$ & $\begin{array}{l}\tilde{a} \\
\dot{n}\end{array}$ \\
\hline $\begin{array}{l}\text { 10. of } 64 / 60 \mathrm{~Hz} \\
\text { 1. trensitions. }\end{array}$ & 0405 & |06 09 & & & & & & 0 & & & & & 30 & 32 & & & & & 41 & 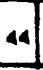 & & 47) & & & & 35 & 58 \\
\hline
\end{tabular}

Fig. 16 Permanent magnetometer telemetry transmission times. 


\subsection{Larse Sen Unit}

The Larse sen unit converts the parallel data to serial permitting transmisson on a single line. The unit converts the 16 bits of output from the counter-sequencer circuit to a serial train of binary coded digital pulses. The unit transmits the 16 bits of data and an internally generated synchronizing code, making a total of 33 bits (one data word) at 60 bits per second (bps). Controlled by the counter-sequencer circuit, the sen unit transmits repeated data words while both the warm up and send commands are activiated (figure 15). Four repeated data words are transmitted during each transmission cycle at the times shown in Figure 16. The Larse sen unit requires +12 VDC at $70 \mathrm{ma}$ and +5 VDC at 70 ma to operate. The +12 VDC open collector output of the unit is connected to the input of the FSK oscillator.

\subsection{FSK Oscillator}

The FSK oscillator (E. Jensen, Oral communication, 1978) is a low power ( $<25 \mathrm{mw}$ ) CMOS circuit using a crystal reference oscillator to provide two output frequencies which are switched by the serialized digital data. One frequency represents a logical " $O$ " and the other a logical "l". The output of the FSK oscillator changes synchronously with the digital input.

\subsection{Relay}

The relay switches the output of the FSK oscillator on to the communication link allowing stations to be time shared at one frequency range. The relay is activated by a +5 VDC signal controlled by the relay command from the counter-sequencer circuit.

The FSK oscillator and relay are the final components separating the permanent magnetometer data from the communication link. The data are transmitted to Menlo Park, California where they are received and recorded (see sections on telemetry receive and record system).

\subsection{Power}

Each permanent magnetometer station is powered by seven McGraw-Edison (model ST-2-1000) air polarized batteries in series. Each battery provides 2.5 volts for $1000 \mathrm{amp}-\mathrm{hr}$ with a maximum current of one amphere. This provides 12.5 VDC (first five batteries in series) and 17.5 VDC for 15-18 months. Each sample requires less than $9 \mathrm{w}$ during sensor polarization, less than $4 \mathrm{w}$ during telemetry transmission, and less than $40 \mathrm{mw}$ in stand-by mode. If a permanent magnetometer station uses a radio for telemetry transmisson five additional McGraw-Edison batteries are required.

\subsection{DESIGN DETAILS OF PORTABLE MAGNETOMETER}

\subsection{General Description}

Figure 17 is a block diagram of a portable magnetometer station. Portable stations record data on a low power digital impact printer (model CR-50) manufactured by Campbell Scientific, Logan, Utah and uses the Geometrics model G-826 magnetometer. All other circuits were designed at the USGS by V. Keller, R. Mueller and B. Smith. The portable magnetometer is very similiar to the permanent, but instead of a telemetry system the portable has an internal CUT clock and on-site digital recording system. 


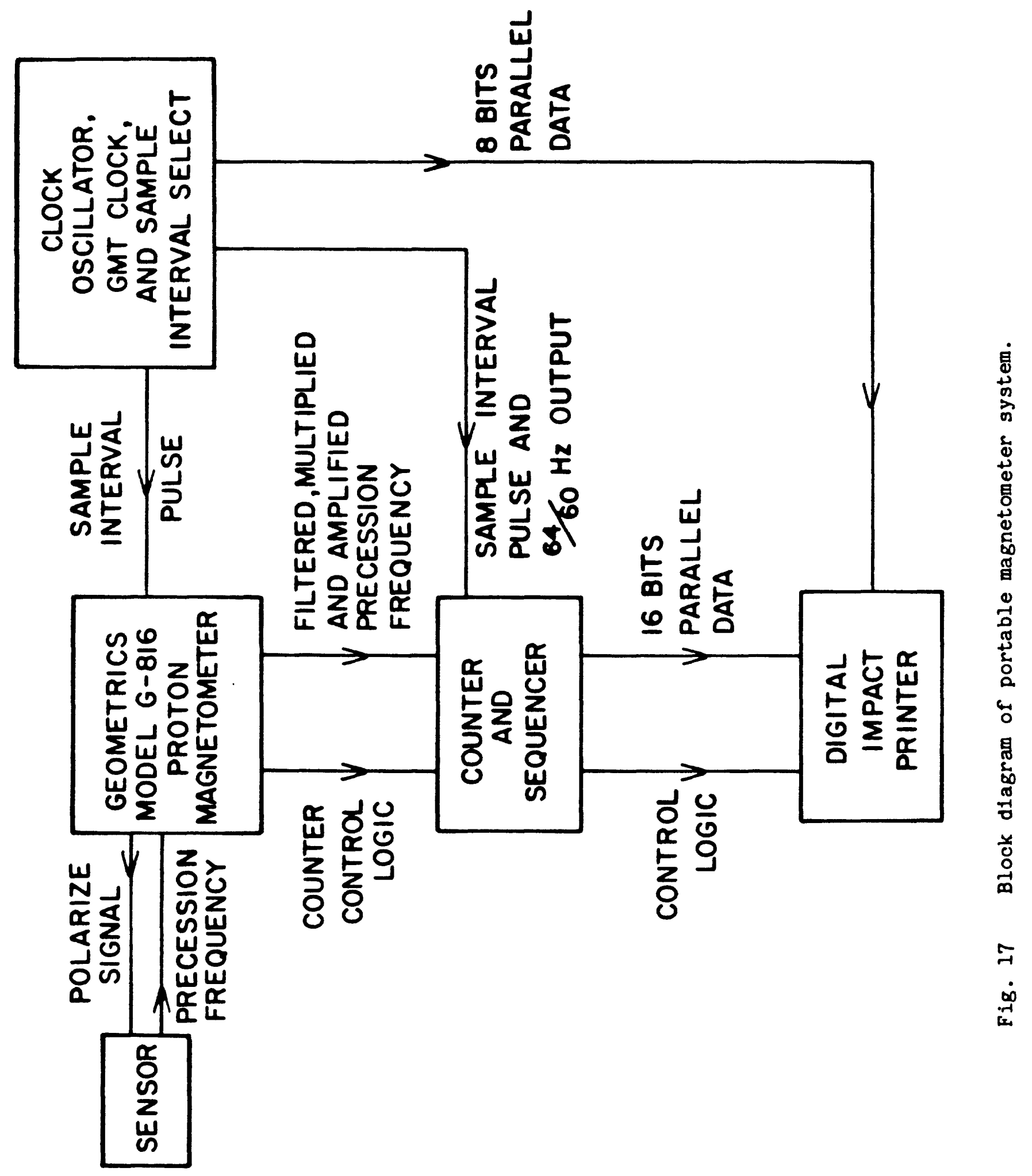


The procedure to sample the magnetic field intensity is identical to the permanent magnetometer station (see permanent magnetometer section) and the procedure for recording the field intensity is as follows (figure 17).

1. After the 16 bits of data are held on the outputs of the countersequencer circuit, power is switched to the digital printer by the warm up command from the counter-sequencer circuit (figure 14 and 15).

2. The send command from the counter-sequencer circuit commands the printer to print 24 bits of data.

3. The turn-off reset command from the counter-sequencer circuit turns the printer off and resets the logic.

\subsection{On Site Recording System}

The recording system consists of three low power CMOS components:

1. The counter-sequencer circuit.

2. The CUT clock and sample interval circuit.

3. The model CR-50 digital printer.

The counter-sequencer circuit for the portable magnetometer is a modified version of the circuit used for the permanent magnetometer station (figure 14). Modifications to the counter-sequencer circuit consist of changing the 16 data outputs from +5 VDC logic to +12 VDC logic by putting +12 VDC at pin 1 of IC 4-6; the output of pin 1 of IC 12 is connected to pin out 30 of connector $\mathrm{J2}$, the output at pin 15 of IC 12 is connected to pin-out $k$ of connector J2, and parts T1, T2, IC 13, COM 1 and COM 2 are eliminated. The +12 VDC to power the Larse, pin out $k$, is used to power the printer; the send command to Larse, pin out 30 , is used to command a print cycle; and the turn off reset command, pin 15 of IC 11 , is used to turn off the printer and reset the logic (Figure 14). The relay command or VCO turn on is not used in the portable magnetometer station. The timing of the command logic on the counter sequencer circuit can be selected for any time between 4 and 90 seconds after the sample interval pulse. For convenience, the portable stations power the printer on the sixth positive transition of the $64 / 60 \mathrm{~Hz}$ signal after the sample interval pulse, print the data at the eighth, and turn the printer off at the ninth.

In order to record on-site, a method to record the time of day is needed. The CUT clock and sample interval circuit use the $1 / 60 \mathrm{~Hz}$ output of the clock oscillator (see clock oscillator section) for time of day and use the $64 / 60 \mathrm{~Hz}$ or $1 / 60$ outputs for determining the time interval of data sampling. Time of day is counted on a divide-by-60 (minutes) and a divide-by-24 (hours) cascaded counting chain (IC 7-10, CD4029AE) (figure 18). The seven bits representing hours and the six bits representing minutes are alternatively latched to the printer through two dual 4-bit latches (IC 11 and 12, CD4508AE). Alternate printing of minutes and hours is controlled by the sample interval pulse clocking a J-K flip flop (IC 2, CD4027AE) and the outputs of the flip flop controlling the enables on the two latches (figure 18). The preset enable (pin 1, IC 7) of the divide-by-24 count chain resets the counters and commands the printer to skip a line marking the start and the end of a day. The counters can be preset to any time by setting the time on a thumbwheel switch and switching two preset toggles. 


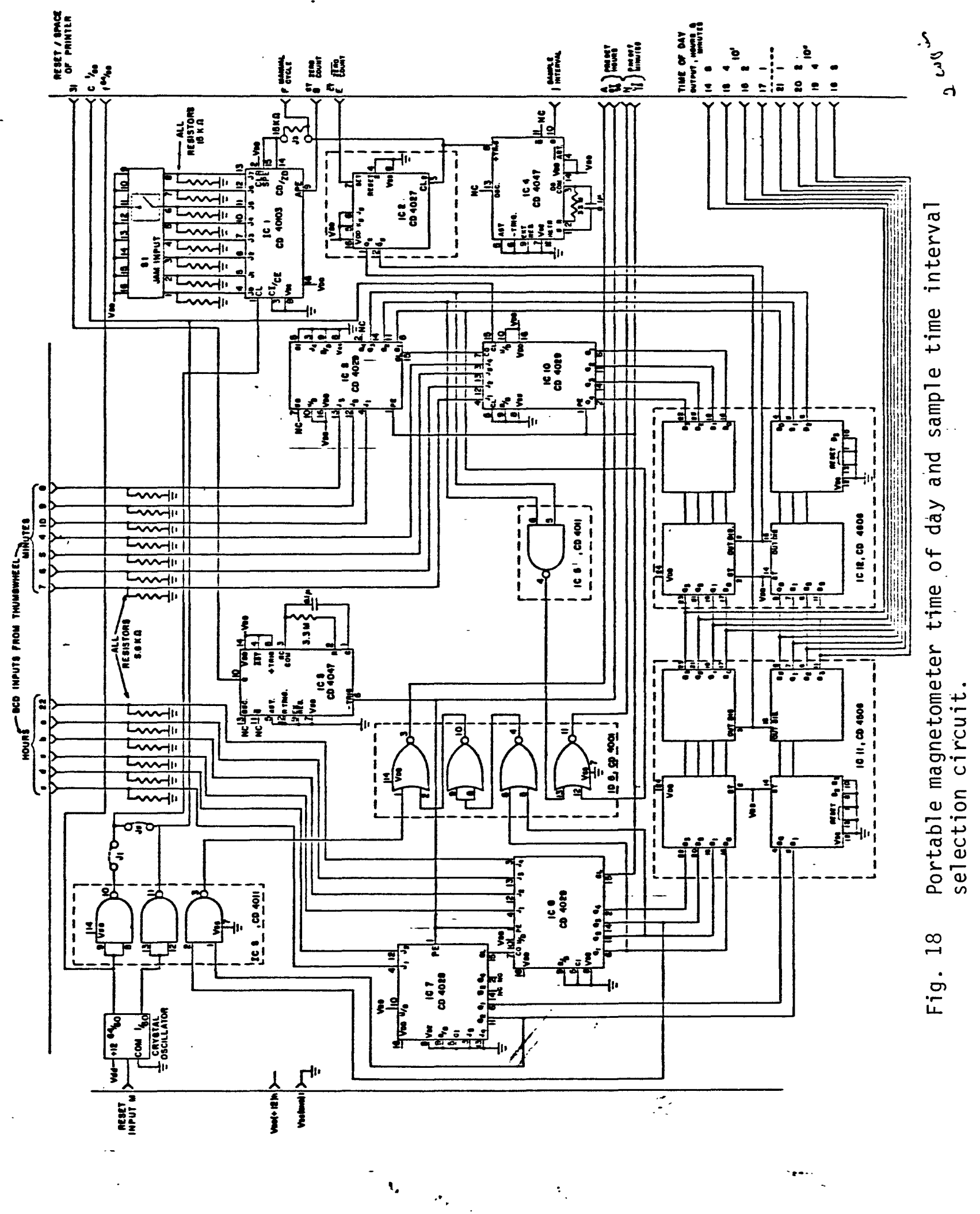


Sample interval selection is determined by switching eight toggles controlling the $\mathrm{jam}$ inputs to a divide-by-N counter (IC 1, CD4103AE). Either the $64 / 60 \mathrm{~Hz}$ or the $1 / 60 \mathrm{~Hz}$ inverted outputs of the clock oscillator can be used to clock the counter. A selection of sample intervals from 5 seconds to 8.5 hours is possible.

The model CR-50 digital printer is a lower power (6w maximum) device with a decimal six digit data format. Two digits represent time of day and the remaining four digits represent the magnetic field intensity. Using a ten minute sample interval and standard fan fold paper pack, 50 days of data can be recorded. The printed data are key punched and read into a computer, where means and standard deviations are computed (see magnetometer arrays section).

\subsection{Power}

Portable magnetometer stations are powered with a 12 volt car battery and a 6 volt gel cell in series. Using a ten minute sample interval the station will operate 60 days before batteries require changing.

\subsection{DESIGN DETAILS FOR MAGNETOMETER TELEMETRY RECEIVER AND RECORDER SYSTEM}

\subsection{General Description}

Figure 19 is a block diagram of the magnetometer receiver and recording system at Menlo Park, California. Commercial components purchased for the system are: the Larse rede unit (REDE 271-60-0) produced by Larse Corporation, Santa Clara, California; the analog recorder (model MIIE) produced by Westronics, Inc. Fortworth, Texas; the digital tape recorder (model 70H) produced by Cipher Data Products, San Diego, California; and the PDP 11/03 computer system. All other circuits are developments of the U. S. Geological Survey, by B. Smith, M. J. S. Johnston, G. Myren, J. Rodgers, B. Mueller, J. Sharp, J. Everhart and J. Johnson. The permanent magnetometer stations transmit data through a communications line by frequency modulating a serial train of binary pulses (see telemetry transmission section). The data arrive at Menlo Park via commercial phone lines and the step by step procedure for receiving and recording is as follows (figure 19):

1. The frequency modulated data are filtered and converted to a serial train of TTL compatiable binary logic pulses by the discriminator.

2. The switching circuit directs the output from one discriminator to the input of one of eight Larse rede units.

3. The Larse rede unit converts the data from serial to 16 bits of parallel data.

4. The data outputs from the Larse rede units and error flag from the data acceptance circuit are connected to the interface.

5. The interface transfers the data, error code, station ID and CUT time onto a digital tape recorder and a PDP $11 / 03$ computer system.

The magnetic tapes record data samples for each permanent magnetometer every 10 minutes and the tapes are read into a computer every 5-7 days. In addition to the tape recording the data are transferred to a PDP $11 / 03$ computer. A digital difference is created from the outputs of two Larse rede units, representing the data from two adjacent magnetometer stations. The digital difference is converted to analog and recorded on a strip chart recorder. The analog record is used for detection of station malfunctions at all permanent magnetometer stations. 


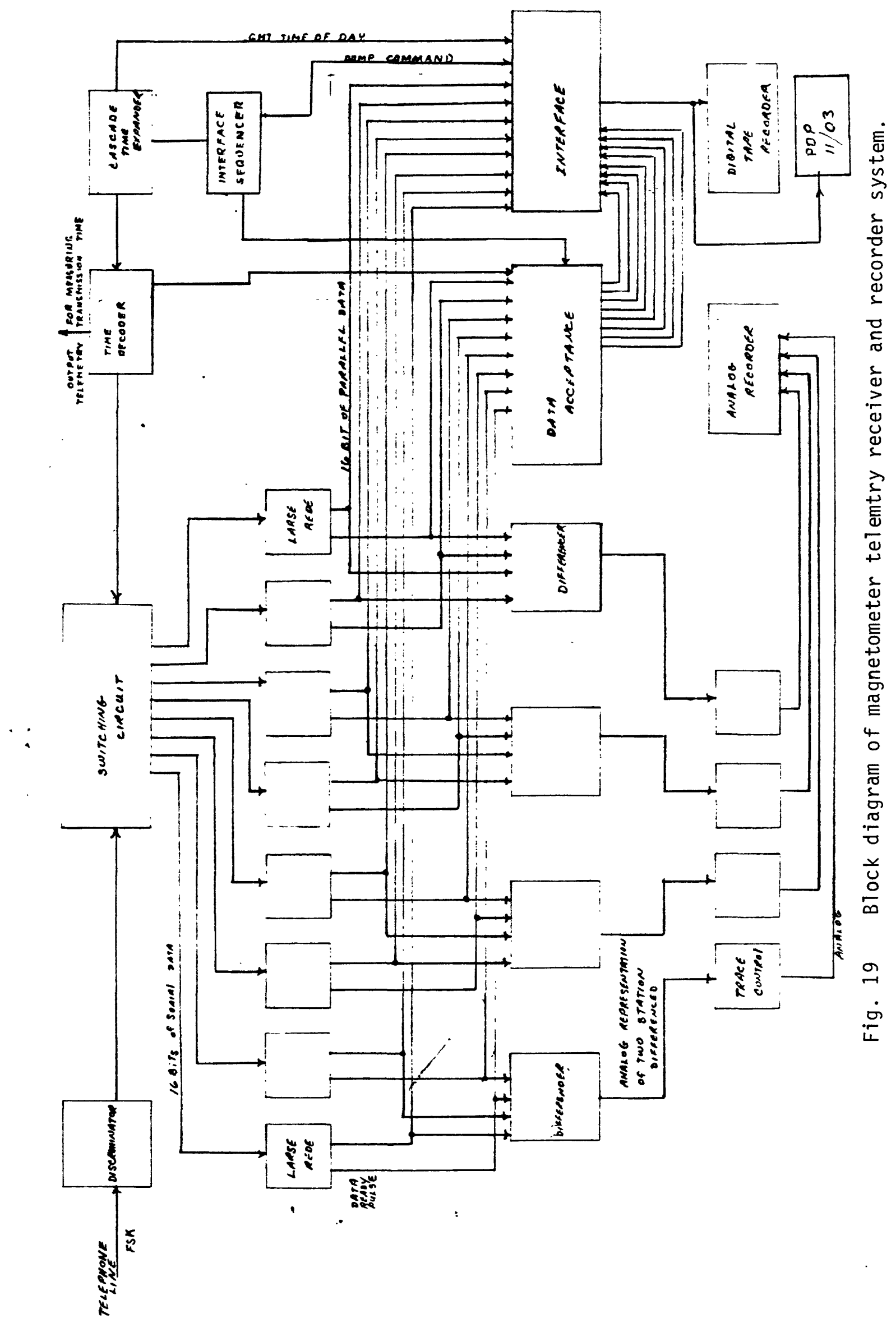




\subsection{Discriminator}

The 3110 discriminator is an analog or digital discriminator capable of accepting frequencies between $380 \mathrm{~Hz}$ and $3060 \mathrm{~Hz}$ (Johnson, 1978). It operates on either analog or digital input. The discriminator filters the desired frequency range from the 10-11 frequency ranges multiplexed on a single telephone line. Each discriminator filters and converts the data from a maximum of eight magnetometer stations. After filtering, the discriminator converts the two modulated frequencies into a train of TTL compatible digital pulses. The output of the discriminator is connected to the switching circuit.

\subsection{Switching Circuit}

The switching circuit (figure 20 ) is designed to sequentially switch the output from one discriminator to the inputs of eight Larse rede units. This allows serial data from a maximum of eight field stations to time share data transmissions at identical FSK frequencies on one telephone line. The ninecontrolling logic pulses from the time decoder circuit (see time decoder circuit section) control the switching circuit to provide time windows during which the field stations must transmit to have the data accepted (figure 21 ). Each time window directs the serial output from the discriminator to the input of a specific Larse rede unit.

\subsection{Larse Rede Unit}

The Larse rede unit receives the serial data, performs several transmission security checks, and converts the data to a 16 bit parallel format. A data ready pulse indicates the data transmission has passed all security checks and is used as an error flag for stored and differenced data. The data outputs of each Larse unit, representing the data from one magnetometer field station are connected to the interface and differencer circuit (figure 19). The data ready pulse is connected to the differencer and data acceptance circuit.

\subsection{Data Acceptance}

The data acceptance circuit (figure 22) is controlled by the data ready pulses from the Larse rede units and the nine time pulses from the time decoder circuit (figure 23). The purpose of this circuit is to create an error flag for the recorded data.

The data ready pulses from the Larse rede units are gated to digital switches (IC $6-9,7401$ ) by the time window outputs from IC 3 , (figure 22). If a data transmission is not accepted or is transmitted outside the time window the output of the digital switch stays low, indicating the data are invalid. All eight digital switches are reset at 00 seconds by a pulse from the time decoder circuit (load pulse). In addition to the error flag, the digital switches power LEDs to give a visual check for data validity. The outputs of the data acceptance circuit are connected to the interface (figure 19). 
4

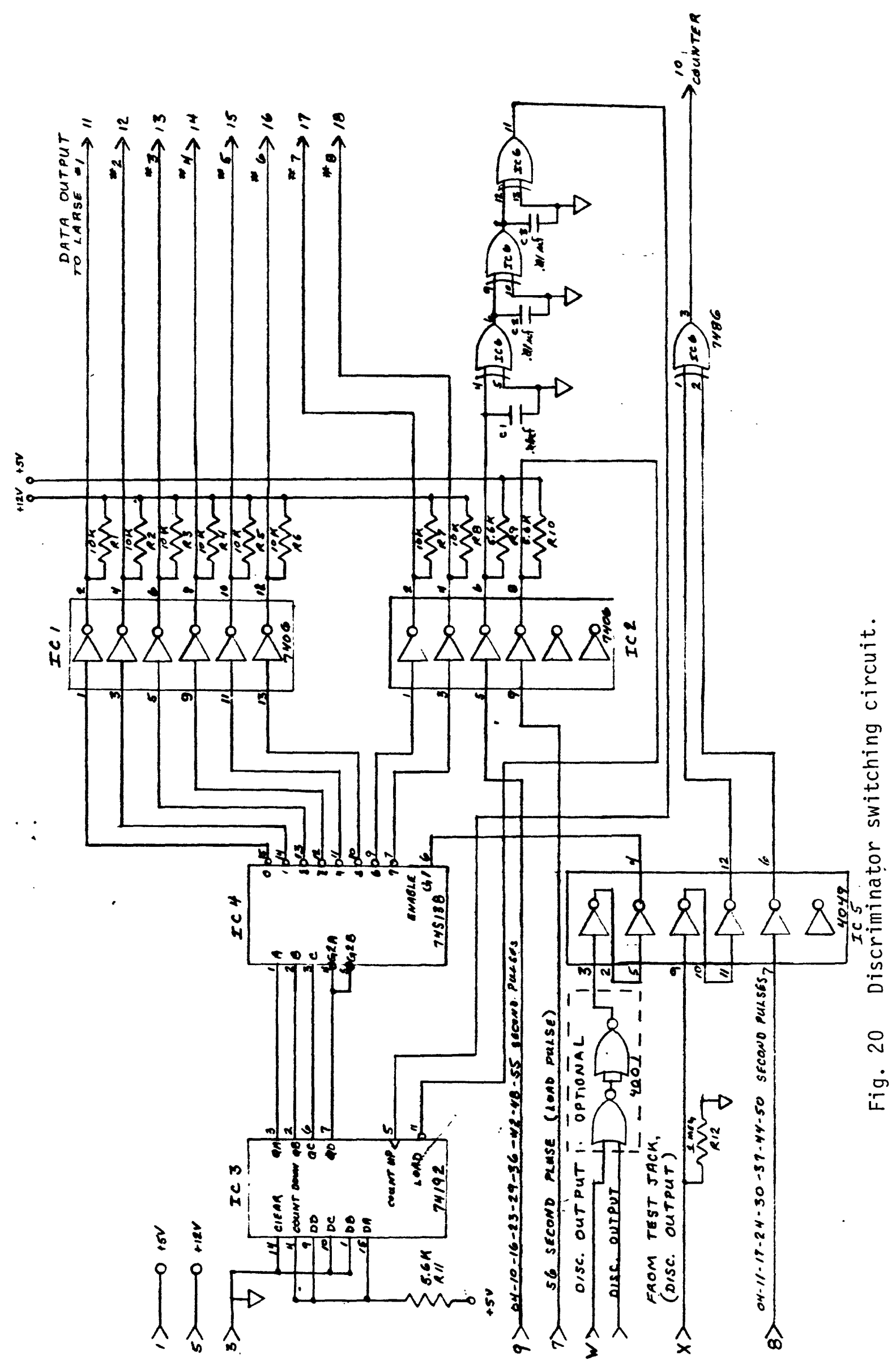




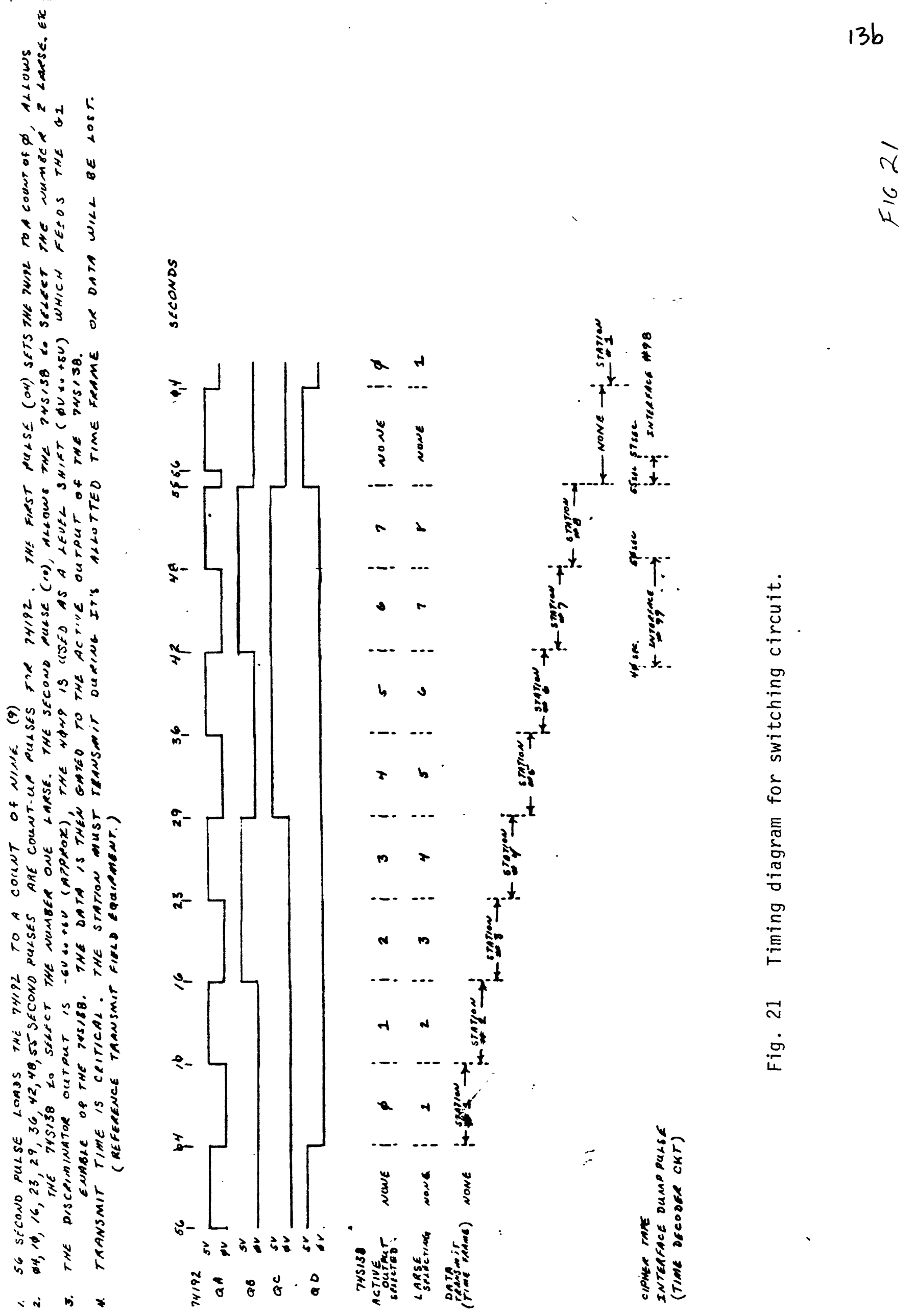




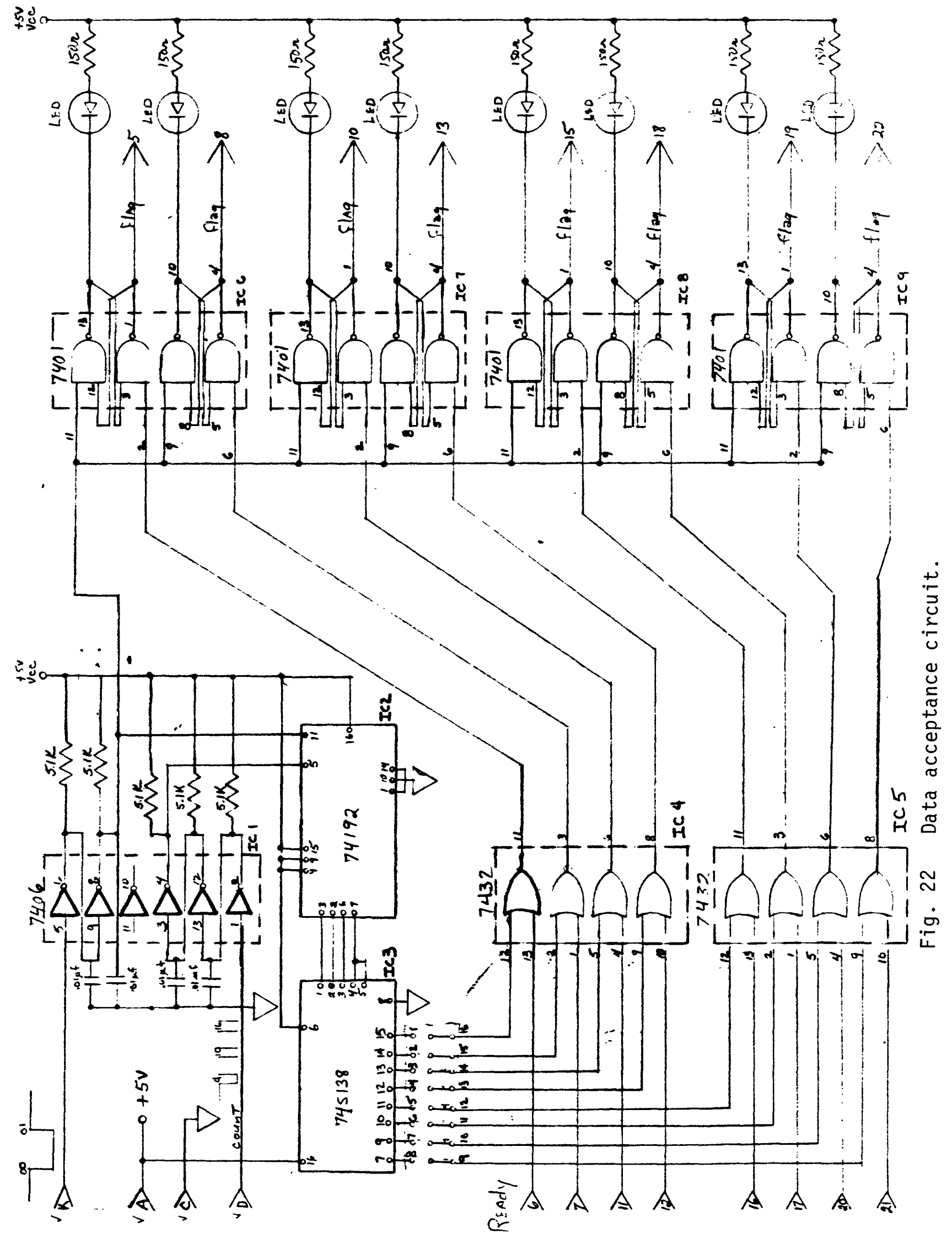

J 


\subsection{Time Decoder}

The time decoder circuit (figure 23) uses parallel BCD time outputs from a time code generater to provide timing logic for the switching circuit and for measuring telemetry transmission arrival time. The BCD time outputs from the time code generater representing units and tens of seconds are converted to decimal logic by two decimal decoders (IC 1 and 2, 7442). The outputs of the two decimal decoders are converted by IC 3-5, (7402) and IC 8 and 9 , (7406) to provide a serial train of nine logic pulses (pinout 16, figure 23). The nine pulses control the logic on the switching circuit and the data acceptance circuit. The outputs from the decimal decoders are also converted by IC, 5-7, (7402) and IC 9 and 10, (7406) to provide a serial train of eight logic pulses (pinout 15) used to monitor field station telemetry transmission timing. Each pulse is the nearest CUT second to the correct warm up command time for the eight sequenced data transmissions (figure 24). Arrival time is monitored by taking a period measurement between the positive transition of the output of the discriminator, caused by the warm up command, and the positive transition of one of the eight logic pulses. This allows the clock oscillator in each field station to be time monitored at Menlo Park, California. A final logic pulse (pinout 11 and 12) is decoded on the time decoder circuit and used to reset the logic on the switching circuit.

\subsection{Digital Recording System}

The interface, cascade time expander, and digital tape recorder are used to record time of day (CUT), station ID, magnetic field data, and error code on a seven track computer compatible tape. The data from the seven track tapes are transferred to a comuputer system. The identical equipment is used for the tiltmeter digital telemetry system and is explained by Roger, et al., 1976. Unlike the tiltmeter telemetry system, a station ID is not transmitted from magnetometer field stations. The data are given a station ID by connecting the outputs from each Larse rede unit to the inputs of an identified data card in the interface. Data from two interfaces (maximum of 30 stations) are transferred onto a single tape once every 10 minutes.

Transferring commands are controlled by the interface sequencer circuit.

The output from the interface also transfers the data to a DEC PDP $11 / 03$ computer system. The PDP $11 / 03$ system is equipped to store 9 days of data on a floppy disk storage system. The data transferring commands and frequency are identical to that used to transfer data to the tape recorders. The tape recording system and PDP $11 / 03$ system are parallel data storage systems. The data stored on the PDP $11 / 03$ system is transferred directly to a PDP $11 / 70$ or the Honeywell 68/80 computer system. All computations, mass storage, and plotting of magnetometer data is completed on the PDP $11 / 70$ or the Honeywell Multics (Multiplexed Information and Computer Service) system.

Presently both the tape recording and PDP $11 / 03$ record and store identical data on two different systems. The PDP $11 / 03$ and the PDP $11 / 70$ or the Honeywell Multics system is used to process magnetometer data, and the tape recording system is used as a back up for the PDP 11/03 system. 
$14 a$

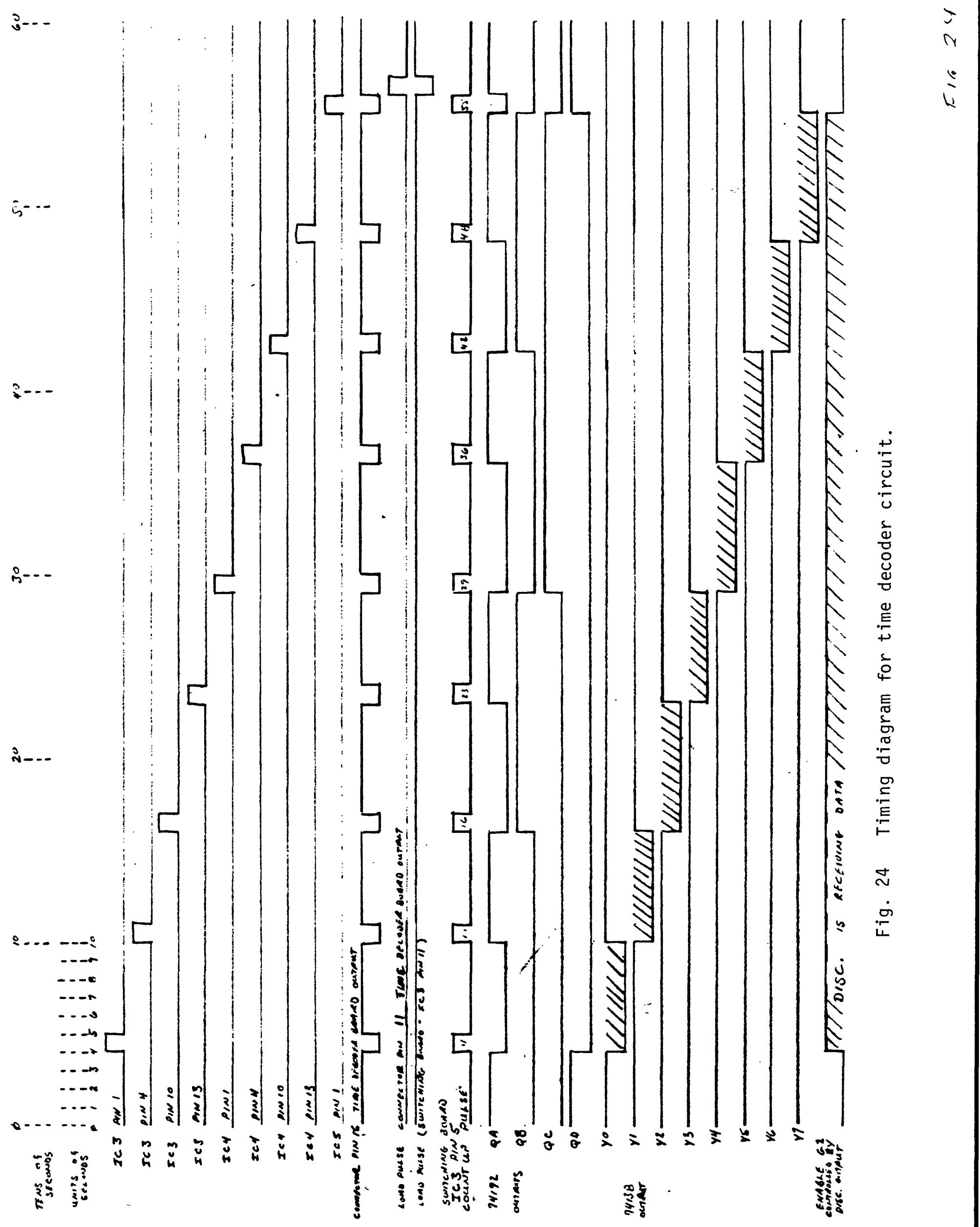




\subsection{Interface Sequencer}

The interface sequencer circuit (figure 25) decodes CUT to provide the sequencing logic for transferring data to data storage systems and resetting the digital switches on the data acceptance circuit (figure 22). The tens of minutes, tens of seconds, and units of seconds are converted by three decimal decoders (IC 1-3, 7442). The outputs of the decimal decoders are inverted (IC 5,7404 ) and decoded (IC 6, 7432) to provide a pulse from 00-01 seconds for resetting the data acceptance circuit and two pulses that command the interfaces to transfer the data to the tape recorder and the PDP 11/03. The two data transfer command pulses (dump pulses) occur from 55-57 seconds and 58-00 seconds after each 10 minute time interval. The dump pulses also power two LED's for visual logic monitoring.

\subsection{Analog Recording System}

The differencer circuit, trace control circuit, and analog recorder (figure 19) are used to record differenced magnetometer data for real time monitoring. The analog recording system is not essential to the telemetry receiver system, but aids in troubleshooting and maintenance of the magnetometer field stations.

\subsection{Differencer}

The differencer circuit (figure 26) receives data from two Larse rede units, calculates a difference, and converts the eight least significant bits (LSB) of the difference value to a 0-10 volt analog output. The 12 LSB's from the Larse rede unit having the lowest magnetic field value of the two stations being differenced and the eight LSB's from the unit having the highest magnetic field value are loaded onto five decade counters (IC 6-10, 74192) (figure 26). The data ready pulses from each of the two Larse rede units are connected to the input of two one shots (IC 2 and 3,555). The time constant of each one shot is set for a 30 second interval and this output controls the loading and count-down of the five decade counters (figures 26 and 27). The counters are sycronously counted down using the output frequency $(-100 \mathrm{kHz})$ of an astable multivibrator (IC 1,555 ). When the count of the three counters (IC 6-8), representing the low magnetic field value, reach zero the borrow output at pin-out 13 of IC 8 turns the counting off and latches (IC 11, 74100) the data out from IC 9 and IC 10 to the input of the digital to analog (D/A) converter (figure 26). The eight bits of output from IC 9 and IC 10 represent the two least significant digits of the difference between the data from two magnetometer stations. The analog output from the differencer circuit is connected to the trace control circuit.

\subsection{Trace Control}

The trace control circuit (figure 28) consists of two operational amplifiers (LM1458) which control the gain and dc offset of the analog input from the differencer circuit. The purpose of the circuit is to control the sensitivity and placement of the 24 channels on the analog recorder to reduce trace crowding and over printing. Each trace control circuit handles two analog signals and the outputs are connected to the analog recorder. 


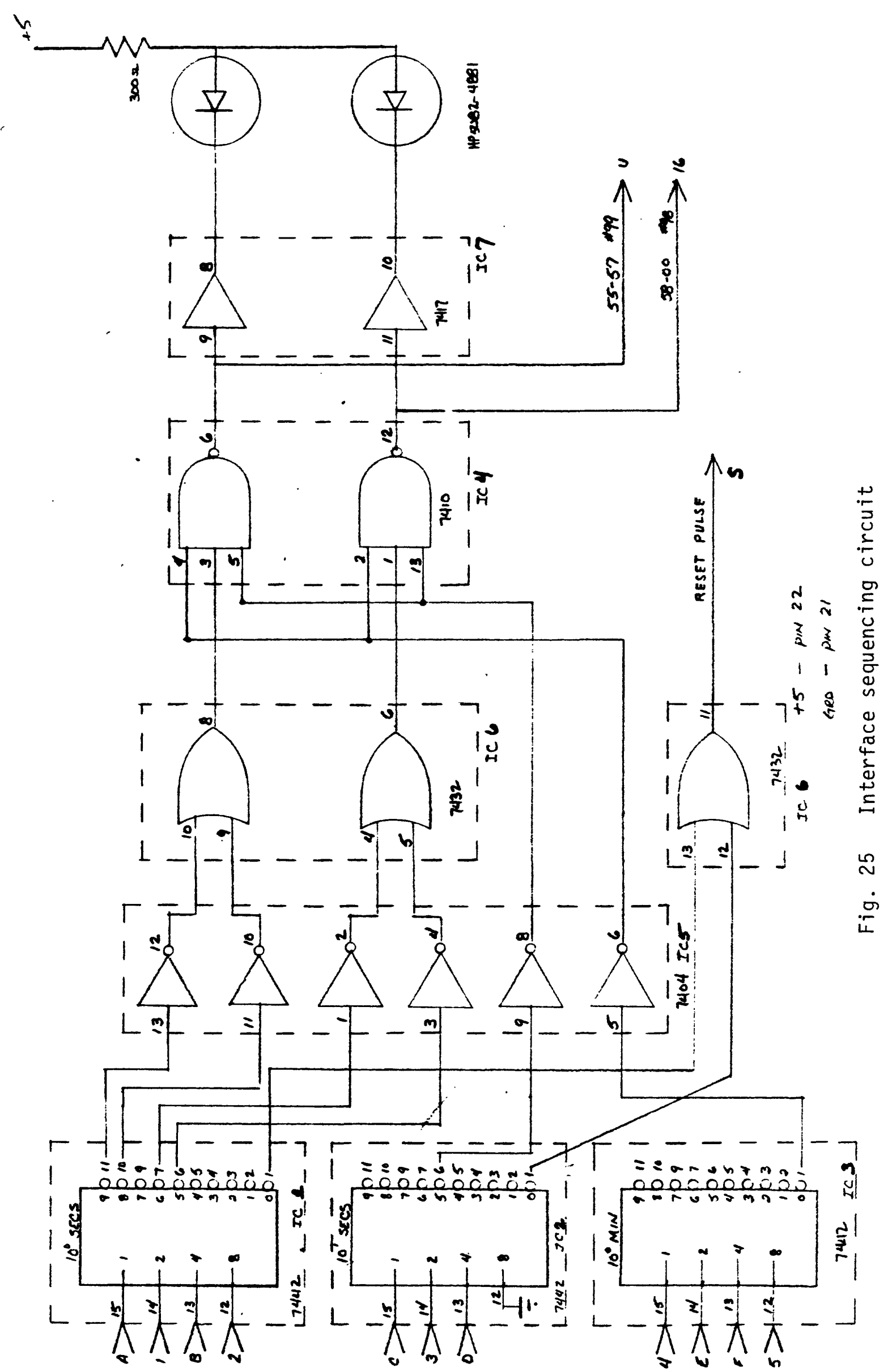




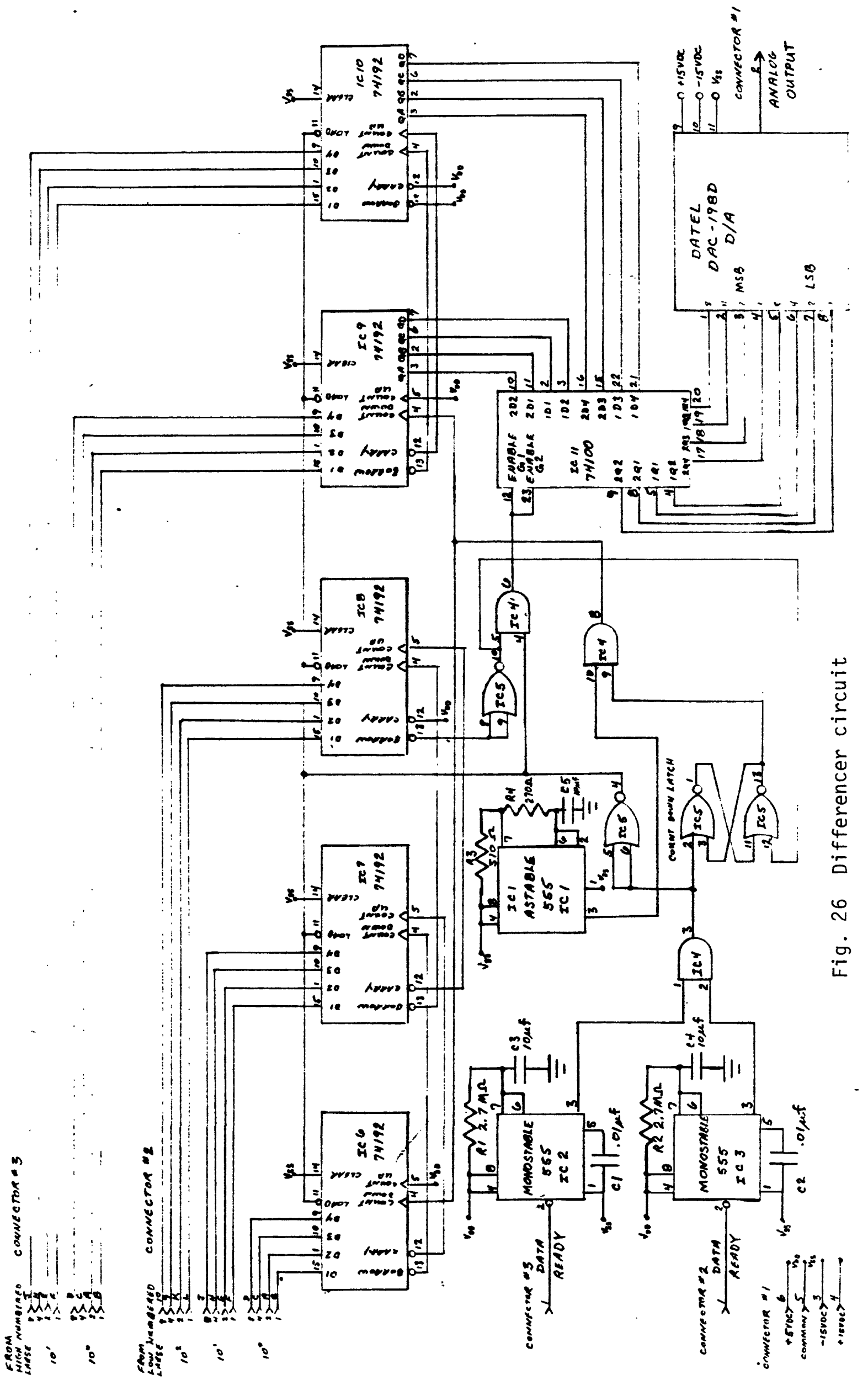


$15 \mathrm{c}$

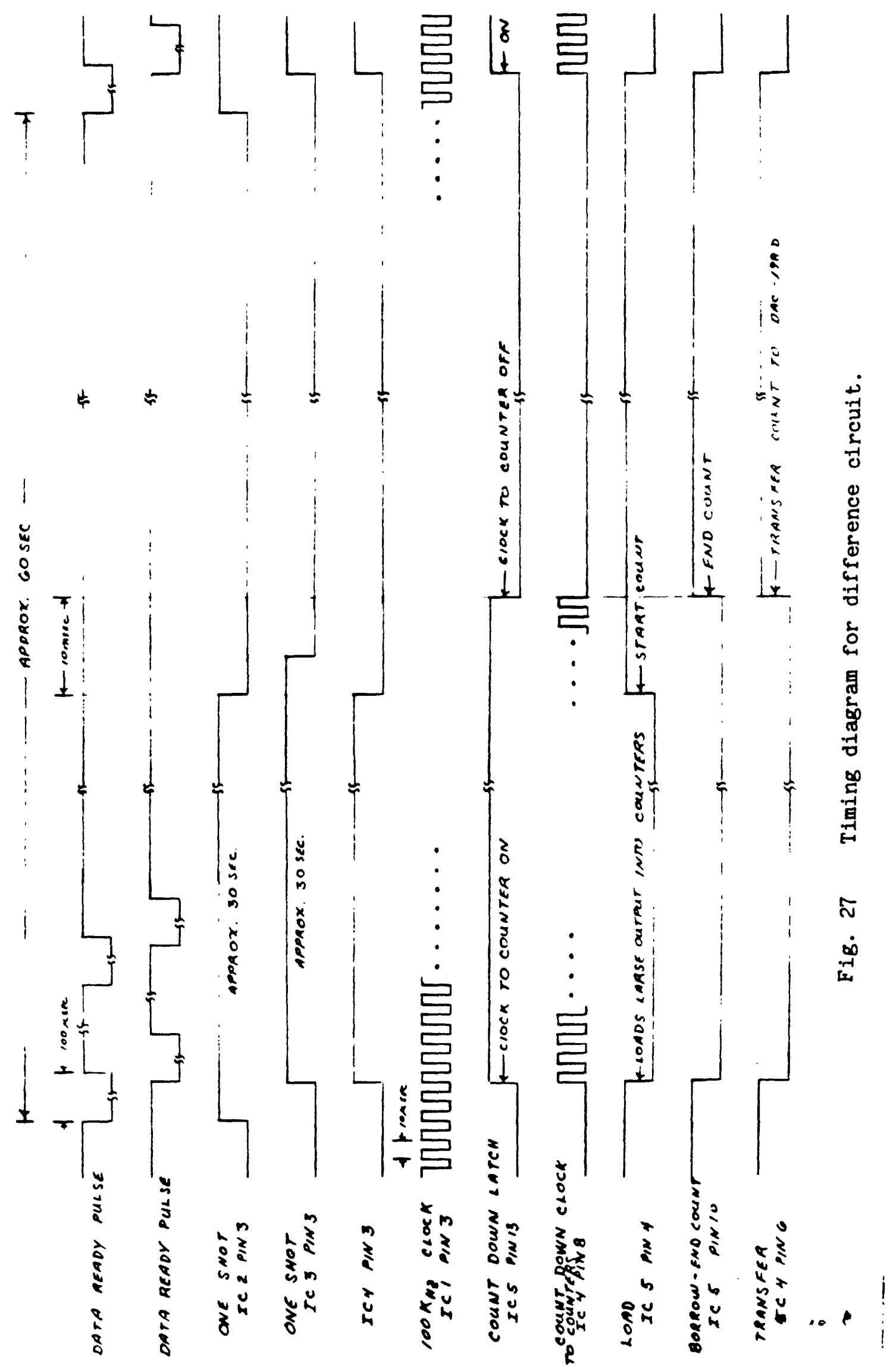


$15 d$

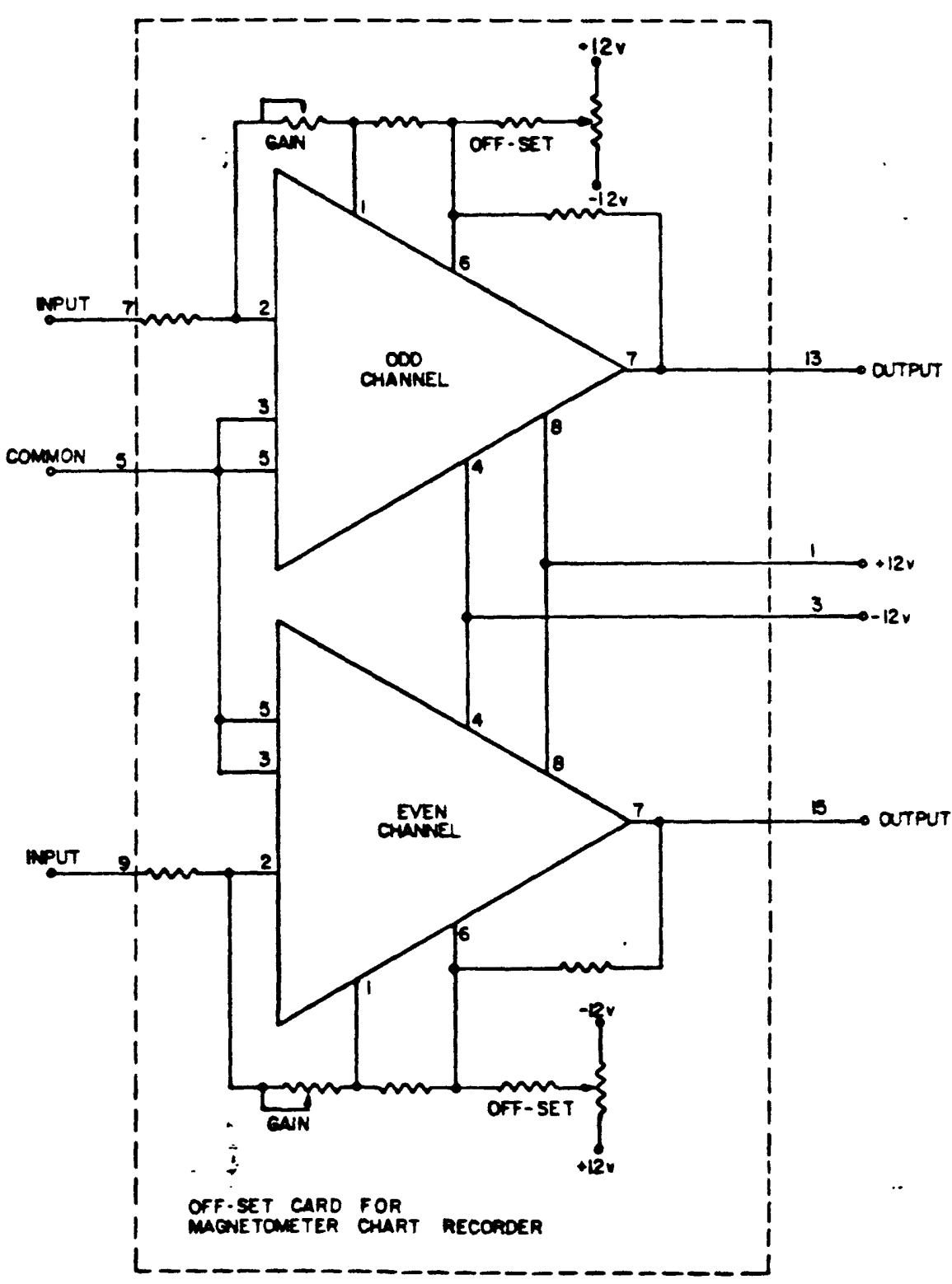

Fig. 28 Trace control circuit. 


\subsection{Analog Recorder}

The Westronics 24 channel analog recorder is used for real time monitoring of magnetometer station differences. The records are useful for detecting and troubleshooting malfunctions in the permanent magnetometer system. The analog representation of differenced magnetometer data is recorded at a chart speed of one quarter inch per hour.

\subsection{Power}

The telemetry receive and recording system uses $+5 \mathrm{VDC},+12 \mathrm{VDC},+15 \mathrm{VDC}$, $-15 \mathrm{VDC}$, and $110 \mathrm{VAC}$. The $110 \mathrm{VAC}(<10$ amps) powers all DC power supplies, the Westronics recorder, and the Cipher tape recorder. Voltages for each circuit are given on the schematic. 


\section{REFERENCES}

Driscol1, R. L., and Bender, P. L., Proton gyromagnetic ratio, Phys. Rev. Letters, 1, 413-414, 1958.

Johnson, J., JTio Discriminator, U.S.G.S. Open File Report, 1979, Menlo Park,CA Johnston, M. J. S., Preliminary results from a search for regional tectonomagnetic effects in California and western Nevada, Tectonophysics, 23, 267, 1974.

Johnston, M. J. S., B. E. Smith and R. Mueller, Tectonic experiments and observations in western U. S. A., J. Geomag. Geolec., 28, 85-97, 1976.

Kalashnikov, A. C., The possible application of magnetometric methods to the question of earthquake indications, Tr. Geofiz. Inst., Akad. Nauk. S.S.S.R., Sb. Statei, 25, 162-180, 1954.

Kapitsa, S. P., Magnetic properties of eruptive rocks exposed to mechanical stresses, Izv. Akad. Nauk S.S.S.R., Ser. Geofiz., 6, 489-504, 1955.

Nagata, T., Basic magnetic properties of rocks under the effects of mechanical stresses, Tectonophysics, 9, 167-195, 1970.

Ohnaka, M., and H. Kinoshita, Effect of uniaxial compression on remanent magnetization, J. Geomag. Geolec., 20, 93, 1968a.

Ohnaka, M., and H. Kinoshita, Effect of axaial stress upon initial susceptibility of an assemblage of fine grains of $\mathrm{Fe}_{2} \mathrm{TiO}_{4}-\mathrm{Fe}_{3} \mathrm{O}_{4}$ solid solution series, J. Geomag. Geoelec. 20, 107, 1968b.

Roger, J., M. J. S. Johnston, C. Mortensen, and G. Myren, A multi-channel digital telemetry system for low frequency geophysical data, U.S.G.S. Open File Report 77-490, 1977, Menlo Park, CA.

Shamsi, S., and F. D. Stacey, Dislocation models and seismomagnetic calculations for California 1906 and Alaska 1964 earthquakes, Bull. Seismol. Soc. Am., 59, 1435-1448, 1969.

Stacey, $F . D .$, Theory of magnetic susceptibility of stressed rocks, Phil. Mag. $7,551-556,1962$.

Stacey, F. D., and M. J. S. Johnston, Theory of piezo-magnetic effects in titanomagnetite bearing rocks, Pure a Applied Geophys., 95, 50-59, 1972.

Vigoureux, P., Gyromagnetic ratio of the proton, Nature, 198, 1188, 1963. 


\section{FIGURE CAPTIONS}

Fig. IA Locations of permanent (solid dots) and portable (open dots) magnetometer stations in central California.

Fig. 1B Locations of permanent (solid dots) and portable (open dots) magnetometer stations in central California.

Fig. 2A Locations of permanent (solid dots) and portable (open dots) magnetometer stations in southern California.

Fig. 2B Locations of permanent (solid dots) and portable (open dots) magnetometer stations in southern California.

Fig. 3 Illustration of permanent (A), portable (B), and survey (C) magnetometer stations.

Fig. 4 Electronics case for a permanent magnetometer station

Fig. 5 Battery enclosure for permanent magnetometer station.

Fig. 6 Sensor post and electronics closure at a permanent magnetometer station.

Fig. 7 Electronics case for a portable magnetometer station.

Fig. 8 Location of survey magnetometer stations in California and western Nevada.

Fig. 9 Block diagram of permanent magnetometers.

Fig. 10 Permanent magnetometer clock oscillator and sample time interval selection circuit.

Fig. 11 Geometrics model G-816 electronic console and sensor.

Fig. 12 Circuit allowing automatic cycling of the model G-816.

Fig. 13 Circuit diagram of Geometrics model G-816 magnetometer.

Fig. 14 Permanent magnetometer counter-sequencer circuit.

Fig. 15 Timing diagram for counter-sequencer circuit.

Fig. 16 Permanent magnetometer telemetry transmission times.

Fig. 17 Block diagram of portable magnetometer system.

Fig. 18 Portable magnetometer time of day and sample time interval selection circuit.

Fig. 19 Block diagram of magnetometer telemtry receiver and recorder system.

Fig. 20 Discriminator switching circuit.

Fig. 21 Timing diagram for switching circuit.

Fig. 22 Data acceptance circuit.

Fig. 23 Time decoder circuit.

Fig. 24 Timing diagram for time decoder circuit.

Fig. 25 Interface sequencing circuit.

Fig. 26 Differencer circuit.

Fig. 27 Timing diagram for difference circuit.

Fig. 28 Trace control circuit. 